\title{
Stress-responsiveness influences baseline glucocorticoid levels: revisiting the under 3 min sampling rule
}

Thomas W. Small ${ }^{1 *}$, Sara E. Bebus ${ }^{1}$, Eli S. Bridge ${ }^{2}$, Emily K. Elderbrock ${ }^{1}$, Stephen M.

Ferguson ${ }^{1}$, Blake C. Jones ${ }^{1}$, and Stephan J. Schoech ${ }^{1}$

${ }^{1}$ Department of Biological Sciences

University of Memphis

${ }^{2}$ Oklahoma Biological Survey

University of Oklahoma

* Corresponding author

Email:

twsmall@memphis.edu

Address: $\quad$ Archbold Biological Station, 123 Main Drive, Venus, FL 33960 
1 Plasma glucocorticoid (CORT) levels collected within 3 min of capture are commonly believed

2 to reflect pre-stressor, baseline CORT levels. Differences in these "baseline" values are often

3 interpreted as reflecting differences in health, or the amount of social and environmental stress

4 recently experienced by an individual. When interpreting "baseline" values it is generally

5 assumed that any effect of capture-and-handling during the initial sampling period is small

6 enough and consistent enough among individuals to not obscure pre-capture differences in

7 CORT levels. However, plasma CORT increases in less than 3 min post-capture in many free-

8 living, endothermic species in which timing has been assessed. In addition, the rate of CORT

9 secretion and the maximum level attained (i.e., the degree of stress-responsiveness) during a

10 severe stressor often differs among individuals of the same species. In Florida scrub-jays

11 (Aphelocoma coerulescens), an individual's stress-responsiveness during a 30 min post-capture

12 stressor is correlated with CORT levels in samples collected within 1.5 min of capture,

13 suggesting there is an intrinsic connection between stress-responsiveness and pre-capture CORT

14 levels. Although differences in stress-responsiveness accounted for just $11 \%$ of the variance in

15 these samples, on average, higher stress-responsive jays (top third of individuals) had baseline

16 values twice that of lower stress-responsive jays (bottom third). Further, plasma CORT levels

17 begin to increase around 2 min post-capture in this species, but the rate of increase between 2

18 and 3 min differs markedly with CORT increasing more rapidly in jays with higher stress-

19 responsiveness. Together, these data indicate that baseline CORT values can be influenced by an

20 individual's stress response phenotype and the differences due to stress-responsiveness can be

21 exaggerated during sample collection. In some cases, the effects of differences in stress-

22 responsiveness and the increase in CORT during sample collection could obscure, or supersede,

23 differences in pre-capture plasma CORT levels that are caused by extrinsic factors. 
Keywords: Baseline; Stress response; Glucocorticoid; Individual variation;

25 Hypothalamic-pituitary-adrenal axis; Handling stress

\section{Introduction}

Glucocorticoids (corticosterone and cortisol; CORT) are a hormonal end product of the

29 hypothalomo-pituitary-adrenal (HPA) axis and, while their primary function is metabolic, they

30 have wide-ranging effects on an organism (Sapolsky et al., 2000). During short-term, extreme

31 environmental challenges, high levels of CORT (stress-induced CORT [SI-CORT]) help

32 facilitate the response to, and recovery from, immediate life-threatening circumstances. At the

33 relatively low "baseline" levels commonly found in unperturbed animals, CORT is thought to

34 support the predictable daily and seasonal patterns of changing energetic needs (see Landys et

35 al., 2006; Romero, 2004; Sapolsky et al., 2000).

An important consideration for the measurement of baseline CORT in plasma is

37 the time between initiation of the stressor (e.g., removal from an enclosure, being caught, etc.)

38 and sample collection. Within the first few seconds of encountering a stressor, corticotropin-

39 releasing hormone $(\mathrm{CRH})$ is secreted from the hypothalamus. $\mathrm{CRH}$ travels to the anterior

40 pituitary where it stimulates adrenocorticotropic hormone (ACTH) secretion into general

41 circulation, resulting in increased CORT synthesis and subsequent release from the adrenal

42 cortex "over the course of minutes" (Sapolsky et al., 2000). Much of what is known about the

43 timing and rate of the post-stressor increase in HPA axis activity, including CORT secretion, is

44 derived from studies on captive bred rodents (Dallman and Bhatnagar, 2001). However, the HPA

45 axes of captive-bred animals often respond more slowly and reach lower peak activity in

46 comparison to their free-living counterparts (Awata et al., 2011; Douxfils et al., 2011; Ericsson et 
47 al., 2014; Homberger et al., 2015; Künzl and Sachser, 1999; Plyusnina et al., 2011; Suzuki et al.,

48 2012; Takahara et al., 2014; Trut et al., 2009; Verbeek et al., 2008), suggesting that captive

49 studies will overestimate the time between the onset of a stressor and the subsequent increase in

50 plasma CORT levels in a free-living animal.

51 While some sources indicate that CORT levels start to increase between 3 to 5 min post-

52 capture in free-living animals (Boonstra, 2005; Sheriff et al., 2011), Romero and Reed (2005)

53 conducted the most thorough investigation on this topic and their study has been widely

54 interpreted to support an "under 3 minute rule" as the standard time frame for sampling baseline

55 CORT in birds and some mammals (Johnstone et al., 2012; Owen, 2011). In their study, change-

56 point analyses were used to determine the primary time at which CORT levels began to increase

57 post-capture for five species of songbird and one species of iguana. Each bird species was

58 sampled during at least two, but up to four, different life-history stages (e.g., breeding, molt,

59 wintering, etc.). The iguana species showed no significant change-point within 3 min of capture,

60 but in the 13 songbird data sets, seven had a change-point of 2 min or less, four had change-

61 points at $3 \mathrm{~min}$, and two had no significant change-point, indicating that CORT levels began to

62 rise in less than $3 \mathrm{~min}$ in over half of the data sets. However, even when CORT began to increase

63 within 3 min of capture, levels were still significantly lower than CORT levels after 30 min of

64 capture stress. Based on this, the authors concluded, "Even when samples collected within 3 min

65 do not reflect unstressed concentrations, they will likely be near enough to baseline to be

66 distinguishable from stress-induced concentrations."

67 Although "near baseline" CORT samples are well below levels attained in response to a

6830 min severe stressor, they may still be high enough to obscure important information found in

69 "true" baseline samples. Studies that use baseline CORT levels as a predictor of fitness, or to 
70 investigate whether CORT levels are repeatable, may require greater precision (e.g., Bonier et

71 al., 2009; Ouyang et al., 2011; Small and Schoech, 2015). Further, the changes that occur within

723 min of capture may vary among individuals.

73 Once CORT levels begin to increase in response to a severe stressor, its rate of increase,

74 maximum blood concentration, and the duration of elevation, can differ greatly among

75 individuals in many animal species (Cockrem, 2013a). These inter-individual differences can be

76 transient or they can be repeatable over time (Cockrem, 2013a; Cook et al., 2011; Hruschka et

77 al., 2005; Narayan et al., 2013; Romero, 2002; Small and Schoech, 2015; Wada et al., 2008).

78 These differences also have been linked to among individual differences in behavior, often

79 characterized on a "bold-shy" or "proactive-reactive" scale (Cockrem, 2013b; Koolhaas et al.,

80 1999). For example, great tits (Parus major) that explored a novel environment more slowly had

81 higher "baseline" CORT (collected $<3 \mathrm{~min}$ ) and higher SI-CORT (collected 90 min post-

82 capture) when compared to faster explorers (Baugh et al., 2013). However, CORT levels

83 increased during the 3 min post-capture sampling period and slower explorers had generally

84 higher "baseline" CORT levels in samples collected between 2-3 min post-capture. Baugh et al.

85 (2013) argued that the under 3 min baseline values were "stress-contaminated" and that the

86 higher baseline CORT levels of slower explorers did not represent "differences in true 'baseline'

87 concentrations". This conclusion highlights the potential problems that can arise when

88 differences in stress-responsiveness are not accounted for when measuring "baseline" CORT.

These among individual differences in SI-CORT may be caused by life-long differences

90 in HPA axis activity (i.e., stress response phenotypes; Baugh, 2012; Carpenter et al., 2007;

91 Claessens, 2011; Pottinger and Carrick, 1999). Repeatable among individual differences in HPA

92 axis activity still allow for internal and external cues to modulate an individual's HPA axis 
93 activity, but the degree of modulation may be constrained by the broader phenotype (i.e.,

94 endocrine flexibility/reaction norms; Hau and Goyman, 2015; Taff and Vitousek, 2016).

95 Whether individual differences in HPA axis activity during a sever stressor reflect similar

96 differences in normal CORT regulation at baseline levels is still unclear. It is possible that the

97 observed differences in SI-CORT regulation are entirely independent of baseline CORT

98 regulation given that the biological activity and negative feedback regulation of CORT at

99 baseline and stress-induced levels are primarily regulated through different receptor types

100 (mineralocorticoid and glucocorticoid receptors, respectively; Atkinson et al., 2008; Funder,

101 1997; Landys et al., 2006; Spencer et al., 1998).

In Florida scrub-jays (Aphelocoma coerulescens), individual differences in SI-CORT

103 levels are detectable within weeks of fledging and these differences are repeatable within adult

104 males and females sampled over an eight year period (repeatability score $>0.5$ for both sexes),

105 suggesting that the general magnitude of the CORT stress response (the stress response

106 phenotype) is a largely "fixed" physiologic trait that persists throughout an individual's adult life

107 (Rensel and Schoech, 2011; Small and Schoech, 2015). Similarly, baseline CORT levels in adult

108 males are moderately repeatable, and baseline CORT values are often correlated with SI-CORT

109 values in both males and females of this species.

110 To investigate the relationship between the life-long differences in the magnitude of an

111 individual's stress response and baseline CORT, we first determined which characteristics of the

112 CORT stress response (e.g. rate of CORT increase, timing of negative feedback, rate of decline,

113 etc), were most responsible for individual differences in SI-CORT (area under the curve for

114 samples collected from capture to 30 min post-capture; Cockrem and Silverin, 2002). We then

115 compared CORT levels collected within 3 min of capture and SI-CORT levels to test two non- 
116 mutually exclusive hypotheses. First, differences in the stress response phenotype observed

117 during an acute, severe stressor are indicative of differences in baseline CORT regulation, such

118 that highly stress-responsive individuals (high SI-CORT) also maintain higher baseline CORT

119 levels. Second, differences in stress-responsiveness influence when CORT levels begin to

120 increase (i.e., the change-point) or the rate that CORT increases within 3 min of capture.

121 Because individual differences in SI-CORT are known to be repeatable through the life

122 of adult Florida scrub-jays (Small and Schoech, 2015), SI-CORT will be used as the measure of

123 an individual's "stress-responsive phenotype" and compared to CORT levels collected within 3

124 min of capture. Further, to control for individual variation in CORT values due to experience

125 prior to capture, a repeated measures design was used in which a subset of jays was sampled two

126 or three times within 3 min of capture to investigate within individual changes in CORT values

127 during the "baseline" sampling period.

128 To reduce confusion, throughout the remainder of the manuscript we will use the term

129 "baseline CORT" to refer to the concentration of plasma CORT prior to capture. The term

130 "initial CORT" will be used for samples collected within 3 min post-capture, which are often

131 believed to reflect baseline CORT values. Samples collected after the 3 min initial CORT

132 sampling period will be referred to as "SI-CORT" samples and these SI-CORT values will be

133 used as a measure of an individual's "stress-responsive phenotype". 


\subsection{Study species and site}

Florida scrub-jays are non-migratory corvids that maintain territories year-round in

141 coastal and inland Florida scrub oak ecosystems. Data presented herein were collected from adult

142 (1 year of age or older) males and females from January to March of 2011-2014 as part of our

143 ongoing long-term research on this cooperatively breeding species at Archbold Biological

144 Station (ABS) in south-central Florida $\left(2710^{\prime} \mathrm{N}, 8121^{\prime} \mathrm{W}, 38-68 \mathrm{~m} \mathrm{ASL}\right)$. The study population

145 occupies $9 \mathrm{~km}^{2}$ of scrub habitat in the south 'half' of ABS and has been studied by SJS and

146 colleagues for over two decades (Mumme, 1992; Schoech et al., 1991, 2012; Small and Schoech,

147 2015). All jays in the population are given a unique combination of two or three colored leg-

148 bands and a USGS aluminum band for field identification so they can be monitored from

149 hatching until death (up to $16 \mathrm{yr}$ ). Individuals are sexed using both genetic and behavioral

150 markers. From 2011-2014, 233 Florida scrub-jays (118 female and 115 male; after hatching year

151 or older) were sampled. Of these birds, 131 were sampled in only one year, 62 were sampled in

152 two different years (once per year), 28 were sampled in three years, and 12 were sampled in all

153 four years resulting in 387 captures.

\subsection{Blood sample collection}

Florida scrub-jays were caught in peanut-baited, walk-in Potter traps during the pre- to

157 early-breeding season. Jays were trained to associate the traps with food for three or more days

158 prior to trapping. On the trapping day, traps were constantly monitored and the exact capture

159 time was recorded. When the trap door closed, a stopwatch was started to measure the elapsed

160 time from capture to sample collection. After capture, a researcher removed the bird from the 
161 trap, transferred it to a processing station (typically within 20 meters), and initiated blood

162 sampling as rapidly as possible. Blood samples were collected in heparinized microhematocrit

163 tubes following venipuncture of the brachial vein with a $25 \mathrm{G}$ sterile needle. The first blood

164 sample was collected within 3 min of capture, and in all years, samples were also collected at 5,

16515 , and 30 min post-capture to measure SI-CORT (Romero and Reed, 2005; Schoech et al.,

166 2007; Small and Schoech, 2015; Wingfield et al., 1995). Between collection of the 5, 15, and 30

167 min samples, individual jays were held in a loosely-woven cloth bag in the shade. In 2013, to

168 allow for repeated measures analysis, if a sample was collected in less than 2.5 min post-capture,

169 an attempt was made to collect a second and, in some cases, a third sample before $3 \mathrm{~min}$ had

170 elapsed. For all samples, blood was kept on ice in the field for 1-4 hours until return to the lab

171 where samples were separated into cellular and plasma fractions with centrifugation, after which

172 the plasma portion was drawn off and stored at $-20^{\circ} \mathrm{C}$ until assayed for CORT (see below). All

173 samples were collected between 7-11AM to help control for diel patterns in hormone secretion.

174 In all cases, the total blood volume taken from an individual was below the $1 \%$ body weight

175 safety limit recommended for birds (averaged 0.5\%; max 0.7\%; Owen, 2011). In 2013 and 2014,

176 the time the trap was opened at each site was recorded to measure how long it took to catch each

177 jay, thus allowing us to examine whether there is an anticipatory CORT response caused by an

178 individual's (or other group members') interaction with the open trap. All procedures in this

179 study were approved by the University of Memphis Institutional Animal Care and Use

180 Committee.

181

182

2.3 Corticosterone assays

183 All plasma samples were assayed for CORT during the calendar year in which they were 
184 collected. However, due to changes in corticosterone antibody availability over the four years of

185 the study, samples were assayed using two different protocols. Samples collected in 2011 were

186 assayed with radioimmunoassay (RIA) using the Fitzgerald 20-CR45 antibody (Fitzgerald

187 Industries International, Acton, MA), and samples collected in 2012-2014 were assayed with

188 Cayman 500655 Corticosterone Enzyme-Linked Immunosorbent Assay (ELISA; Cayman

189 Chemicals, Ann Arbor, MI). The values from these assays are highly comparable (see Small and

190 Schoech [2015] for validation of inter-assay comparisons). All samples collected from the same

191 bird in the same year (initial [<3 $\mathrm{min}], 5,15$, and $30 \mathrm{~min}$ ) were run in the same assay.

\subsubsection{Radioimmunoassay}

193

CORT was extracted from plasma samples ( 5 to $40 \mu \mathrm{l}$ ) using diethyl ether. The aqueous

194 fraction of the extraction solution was snap-frozen, the ether fraction containing steroids was

195 poured off, and the ether was evaporated under nitrogen gas. The dried sample was reconstituted

196 in $550 \mu 1$ of phosphate-buffered saline with gelatin. Subsequently, $200 \mu 1$ of the sample in PBSG

197 were aliquoted into duplicate assay tubes to which we also added a known amount of antibody

198 and tritiated corticosterone (Perkin Elmer, Inc.). From the remaining $150 \mu 1,100 \mu 1$ were

199 dispensed into a vial to calculate recovery (see below). A standard curve was prepared by serially

200 diluting CORT standard (2,000-7.8 pg; Sigma Aldrich) and adding the same amounts of labeled

201 CORT and antibody that were combined with the unknown samples. CORT levels were

202 determined by correcting for sample volume and percent recovery (mean recovery was $76.5 \pm$

$2037.3 \%$ [standard deviation; SD]). Percent recoveries were calculated from a small volume of

204 radiolabeled CORT that had been added to samples prior to extraction. Samples from a total of 4

205 assays were included in this study. Two internal controls (IC; i.e., CORT samples of known

206 concentrations) were included in duplicate at the beginning and end of each assay and used to 
207 assess the inter- and intra-assay coefficients of variation (CV). The intra-assay CVs were 5.3\%,

$2086.5 \%, 7.2 \%$ and $10.9 \%$, whereas the inter-assay CV was $6.7 \%$.

$209 \quad$ 2.3.2 Enzyme-linked immunosorbent assays

210 Samples collected in 2012-2014 were assayed with the protocol and reagents provided

211 with the Cayman Chemical ELISA corticosterone kit. Similar to extracted samples in the RIA,

212 the Cayman assay measures total CORT in Florida scrub-jay samples (Schoech et al., 2013;

213 Small and Schoech, 2015). Fifteen plates were used to assay samples in duplicate, and each plate

214 also included IC CORT samples for assessment of intra- and inter-assay variation. The intra-

215 assay CVs range from $1.1 \%$ to $17.8 \%$ (mean 8.3\%) and the inter-assay CVs for 2012-2014 were

$21615.4 \%, 6.1 \%$, and $10.2 \%$, respectively. The inter-assay CV for all years combined was $13.9 \%$.

217 The same Sigma Aldrich CORT stock solution was used to make the ICs for both the

218 ELISAs and the RIAs. However, due to the difference in sensitivity between the two types of

219 assays, the ELISA ICs were prepared at a lower concentration than those of the RIA to ensure

220 that the ICs were distributed on the linear part of the standard curve. When the ELISA ICs were

221 corrected for the dilution difference, the inter-assay CV for all RIAs and ELISAs combined was

$22212.9 \%$.

223

224

225

2.4 Statistical analysis

226 the curve for the capture and restraint stress response (initial, 5, 15, and 30 min samples;

227 integrated CORT). We also calculated the area under the curve after subtracting the initial CORT

228 value from each value in the stress series (corrected integrated CORT; i.e., setting baseline to

229 zero) to evaluate the change in CORT over initial CORT (Cockrem and Silverin, 2002). It is 
unclear whether integrated or corrected integrated CORT values are the more biologically

231 relevant measure of SI-CORT, so all analyses were done with integrated CORT and again with

232 corrected integrated CORT. Results using these two measures of SI-CORT did not qualitatively

233 differ. Only results using corrected integrated CORT are reported because it is the more

234 conservative measure of SI-CORT for this study. By subtracting the initial CORT value from the

235 SI-CORT calculation, the only potential bias introduced is a negative correlation between SI-

236 CORT and initial CORT (the opposite of the predicted direction in this study) because the larger

237 the value of initial CORT, the smaller the corrected integrated CORT value will be in

238 comparison to the integrated CORT value.

239 In Florida scrub-jays, initial CORT and SI-CORT levels decline from 7 to 11AM each

240 day due to a normal diel rhythm in CORT secretion (Rensel and Schoech, 2011; Small and

241 Schoech, 2015; Wilcoxen et al., 2011). To correct for this effect, the residuals from a regression

242 of initial CORT vs. capture time of day (hr since sunrise; $\mathrm{N}=387, \beta=-0.23 \pm 0.11, \mathrm{P}<0.001$ )

243 and the residuals from a regression of SI-CORT vs. capture time of day $(\mathrm{N}=387, \beta=-0.32 \pm$

$2440.11, \mathrm{P}<0.001)$ were used in each analysis.

245 2.4.1 Change-point

246 Similar to the methods of Romero and Reed (2005), non-parametric change-point

247 analysis (Andersen et al., 2009; Pettitt, 1980) was used to estimate the timing of the post-capture

248 increase in CORT. To avoid inclusion of non-independent data, for each jay captured in more

249 than one year, a single sample was randomly selected for inclusion. Also, for jays sampled more

250 than once in less than 3 min, only the 1 st samples were included (see section 2.4 .4 below). First,

251 we calculated the overall change-point for samples collected under 3 min post-capture. Second,

252 to investigate whether SI-CORT phenotype influenced when the post-capture increase in CORT 
253 began, jays were near evenly divided into three SI-CORT categories (see Fig. 1A), and the

254 CORT change-point was calculated separately for each: Low responders (mean: 441 [ng/ml] ${ }^{\times}$

255 min, range: 147-560, $\mathrm{n}=78$ ), Medium responders (Med; 658, 565-759, $\mathrm{n}=77$ ), or High

256 responders $(970,775-1679, \mathrm{n}=78)$.

Prior to analysis, mean initial CORT values were centered for each year to control for

258 inter-annual variation in initial CORT (Schoech et al., 2007; Small and Schoech, 2015). In the

259 change-point analysis, each time point (sampling time post-capture) can only have one value

260 associated with it. Because blood samples took multiple seconds to collect from the brachial

261 vein, and sample times were recorded at the completion of blood collection, if more than one

262 CORT value was associated with the same time point (e.g., three different jays had CORT

263 samples at 2 min post-capture), extra values were moved to unoccupied time points within 3

264 seconds of the original time point. When no earlier time points were available, all CORT values

265 associated with the same time point were averaged. The CORT values were then ranked (ties

266 received a mid-rank) prior to each of the analyses and the change-point was calculated using the

267 mean square error estimator technique in Change-Point Analyzer 2.3 (Taylor Enterprises, Inc.,

268 Libertyville, IL USA; Taylor, 2000). Change-point confidence levels and 95\% confidence

269 intervals (CI) were determined by performing 10,000 bootstrap simulations for each analysis

270 (Hinkley and Schechtman, 1987). The data in each of the four analyses met the assumption of

271 independent error structure (Taylor, 2000).

272

\subsubsection{Rate of CORT increase during 30 min capture and handling stress}

273 To determine when the rate of CORT increase was greatest during the 30 min

274 standardized stressor, and when the greatest differences exist in the rate of increase among

275 individuals with Low, Med, and High SI-CORT responses, we calculated the rate at which 
276 CORT increased for the three time periods between sample collections (i.e., initial to $5 \mathrm{~min}, 5$ to

$27715 \mathrm{~min}$, and 15 to $30 \mathrm{~min}$ ). Rate of change was used instead of comparing absolute concentration

278 of CORT at each time point because the rate of change provides a standardized comparison

279 between samples that were not equally distributed across time. In each case, the absolute change

280 in CORT between sample points was divided by the elapsed time (e.g., [15 min CORT $-5 \mathrm{~min}$

$281 \mathrm{CORT}] / 10 \mathrm{~min})$ to produce a rate of change $([\mathrm{ng} / \mathrm{ml}] / \mathrm{min})$. For these calculations, initial CORT

282 samples used $2 \mathrm{~min}$ as the initial CORT sample time instead of their true sample time because

283 change-point analysis identified $2 \mathrm{~min}$ as the approximate time point when CORT began to

284 increase (see results and Table 1). For samples collected prior to 2 minutes, using the true time

285 would have underestimated the rate of change because it is unlikely that CORT levels

286 appreciably increased prior to $2 \mathrm{~min}$. Similarly, for those samples collected more than $2 \mathrm{~min}$

287 post-capture, the period of time between $2 \mathrm{~min}$ and the true sample time is likely to have the

288 slowest rate of increase in plasma CORT concentration during the first 5 min, thus, including the

289 additional time in the calculation would have less of a biasing effect compared to the

290 overestimation that would result from using the true time.

291 To allow for post hoc comparisons that would more closely test the above stated

292 hypotheses, we subdivided jays into Low, Med, and High SI-CORT categories (see 2.4.1 above).

293 The rate of CORT change (response variable) was compared to SI-CORT using a linear mixed

294 model (LMM) fitted by restricted maximum likelihood with SI-CORT, time period, and subject

295 sex as fixed factors. Subject identity (ID) was included as a random variable nested within SI-

296 CORT (repeated measures approach; Wallace and Green, 2002). Sex was included as a fixed

297 factor because it was previously shown that sex differences exist in the repeatability of initial and

298 SI-CORT values of Florida scrub-jays (Small and Schoech, 2015) indicating that sex differences 
in CORT regulation may exist in this species. Tukey-Kramer HSD was used for post hoc

300 comparisons of means to further investigate significant effects in the LMM.

\subsubsection{Initial CORT and SI-CORT phenotype under $3 \mathrm{~min}$}

The effects of SI-CORT phenotype on initial CORT values were investigated using a

LMM. CORT values from jays sampled once within 3 min of capture $(2011-2014 ; n=350)$ and the first sample collected from jays sampled more than once within $3 \min (2013 ; \mathrm{n}=37)$ were used. Time since capture, SI-CORT phenotype, subject sex, and their interactions were included as fixed factors. The model was first run with SI-CORT and time since capture as continuous data. Similarly, a subsequent model was run with SI-CORT phenotype and time since capture treated as categorical data to facilitate post hoc analyses. SI-CORT phenotype categories were divided into Low, Med, and High (as 2.4.1 above), and time since capture was divided into samples collected between capture and $1.5 \mathrm{~min}$ post-capture $(<1.5 \mathrm{~min})$, between 1.51 and $2 \mathrm{~min}$ ( $2 \mathrm{~min}$ ), between 2.01-2.5 $\mathrm{min}$ (2.5 $\mathrm{min}$ ), or between 2.51 and $3 \mathrm{~min}(3 \mathrm{~min})$. The time categories were selected to coincide with the CORT change-point ( $\sim 2 \mathrm{~min})$ and to generally encompass the change-point 95\% CIs for all three categories of SI-CORT phenotype (Table 1). For both models, year (categorical) was included as a random variable to control for inter-annual variation in initial CORT values and subject ID was included as a random variable to control for birds sampled in more than one year. Tukey-Kramer HSD was used for post hoc comparisons. We estimated the relative effect size of the fixed factors on initial CORT values using two methods. First, we calculated the standardized regression coefficients ( $\beta$ ) which expresses the slope of a line as the number of standard deviations the dependent variable changes per standard deviation of the independent variable. As such, for $\beta$ values we report the slopes and 95\% CIs of each explanatory variable and their interactions in the LMM containing SI-CORT 
322 and time since capture as continuous data, but prior to analysis, all continuous independent and

323 dependent variables were converted to their $\mathrm{z}$-scores and the categorical variable, sex, was

324 converted to a binary variable (Schielzeth, 2010). Second, we used a mixed model analogue of

325 the linear model coefficient of determination $\left(\mathrm{R}^{2}\right)$ called $\mathrm{R}^{2}{ }_{\mathrm{GLMM}}\left(\mathrm{R}_{\mathrm{G}}^{2}\right.$; Nakagawa and Schielzeth,

326 2013) to report the proportion of the variance in the initial CORT values that is explained by the

327 independent variables. Similar to $\mathrm{R}^{2}, \mathrm{R}_{\mathrm{G}}^{2}$ ranges from $0-1$ and is a general expression of the

328 "variance explained" by a model. There are two forms of $\mathrm{R}_{\mathrm{G}}^{2}$ : conditional $\mathrm{R}_{\mathrm{G}}^{2}$ (estimates the

329 variance explained by both fixed and random factors), and marginal $\mathrm{R}_{\mathrm{G}}^{2}$ (estimates the variance

330 explained by the fixed factors alone). Using the sem.model.fits function in the piecewiseSEM

331 package (Lefcheck, 2015) for R statistics (R Core Team, 2015), both conditional and marginal

$332 \quad \mathrm{R}_{\mathrm{G}}^{2}$ were calculated for the LMM model as described above (Time since capture, SI-CORT

333 phenotype, subject sex, and their interactions as fixed factors). To estimate the influence of each

334 fixed factor on its own, both forms of $\mathrm{R}_{\mathrm{G}}^{2}$ were also calculated for three additional models, each

335 containing only one of the three fixed factors. The random variables were the same as above in

336 all four models used to calculate $\mathrm{R}_{\mathrm{G}}^{2}$.

To further investigate the influence of SI-CORT phenotype on initial CORT values, 37

339 jays were sampled either twice $(n=28)$ or three times $(n=9)$ within 3 min of capture during the

3402013 pre-breeding season. Samples were analyzed using a mixed-model repeated measures

341 approach (Wallace and Green, 2002). As above (2.4.3), the repeated measures model was first

342 run with SI-CORT and time since capture as continuous data and a subsequent model was run

343 with SI-CORT phenotype and time since capture included as categorical fixed factors, allowing

344 post-hoc comparisons. Subject ID nested in SI-CORT phenotype was included as a random 
345 variable. Subject sex was not included as a fixed factor due to the smaller sample size and

346 because the prior analysis indicated sex had no effect on initial CORT values. Tukey-Kramer

347 HSD was used for post hoc comparisons.

348 To test if the repeated measures design had carryover effects (i.e., collecting the first

349 sample influenced the CORT values of subsequent samples), samples collected in 2013 from

350 individuals that were sampled only once within 3 min were compared to the second or third

351 samples from individuals that were repeatedly sampled under $3 \mathrm{~min}$. In individuals sampled three

352 times, only the third samples were used so that individuals were included only once in the

353 analysis and because this last sample would likely best detect any carryover effect. Time since

354 capture was limited to the period in which second and third samples were collected (1.8 to 3

$355 \mathrm{~min}$ ). The initial CORT values (response variable) were compared to SI-CORT (continuous),

356 time since capture (continuous), sampling type (single vs repeated samples) and their interactions

357 (fixed factors) in a general linear model (GLM) fitted by least squares.

\subsubsection{Initial CORT and SI-CORT under 1.5 min}

To more closely investigate whether baseline CORT levels covary with, or are a function

360 of, SI-CORT phenotype, the following analysis was restricted to samples collected within 1.5

361 min of capture. The 1.5 min threshold was used because it fell below the lower $95 \%$ CI for the

362 CORT change-point of each for the three SI-CORT categories (Table 1) and thus was unlikely to

363 be influenced by capture stress and likely represented pre-capture baseline values. SI-CORT and

364 time since capture were included as continuous fixed factors in the LMM to increase the power

365 of the analysis and because non-linear relationships were not of interest. Sample year was

366 included as a random variable. 
Similar to 2.4.3, we estimated $\beta$ using the slope and 95\% CIs and conditional and

368 marginal $\mathrm{R}_{\mathrm{G}}^{2}$ for the under 1.5 min LMM model (Time since capture, SI-CORT phenotype, and

369 their interactions as fixed factors) and then for two additional models, containing either time

370 since capture, or SI-CORT phenotype as the fixed factors. The random variables were the same

371 as above in all three models.

\subsubsection{Capture effort}

Jays must enter a trap to be caught and the experience of approaching and interacting

374 with the trap could be a stressor that influences CORT levels prior to capture. The time it takes to

375 catch a jay can vary greatly (mean $34 \pm 37$ [SD] min; median 18; range 1.2-169 min; elapsed

376 time since a trap is set and baited at a site until capture; henceforth, "capture effort"). To

377 investigate whether the pre-capture experience influenced the initial CORT values of Florida

378 scrub-jays, in 2013-2014 we recorded the time a group of jays were first exposed to a baited trap

379 and the exact capture time of each jay thereafter. In the first analysis, capture effort, SI-CORT

380 level, time since capture (all continuous fixed factors) and their interactions were compared to

381 initial CORT values collected within 3 min of capture. Second, the same analysis was repeated

382 but only for samples collected within $1.5 \mathrm{~min}$. Lastly, a subset of data from all birds caught

383 within 10 min of encountering the trap were analyzed to assess whether exposure to the trap had

384 a rapid effect on baseline CORT values that quickly stabilized. Samples collected within 2 min

385 post-capture were used instead of $1.5 \mathrm{~min}$ to avoid the post $2 \mathrm{~min}$ increase in CORT while still

386 providing a large enough sample size for analysis.

388 being captured prior to a jay's own capture could have influenced baseline CORT values

389 independently of capture effort. The order in which jays were captured at a site and capture effort 
were not included as fixed factors in the same analysis because, as expected, they were strongly

391 correlated $\left(\mathrm{F}_{1,175}=98.8, \mathrm{P}<0.0001, \mathrm{R}^{2}=0.61\right)$. When capture effort was replaced with capture

392 order in the first and second analyses, results did not meaningfully differ, so the capture order

393 results were not included.

394 Unless otherwise stated, statistical analyses were performed in JMP 10 (SAS Institute

395 Inc., Arlington, VA.). CORT data were square-root transformed to meet assumptions of

396 normality and homogeneity of variance. For ease of interpretation and comparison, non-

397 transformed values are used in the text, tables, and figures.

\section{Results}

Male and female jays did not differ in any aspect of sample collection (DOY, $\mathrm{F}_{1,381.5}=$

$401 \quad 0.384, \mathrm{P}=0.536$; time since sunrise, $\mathrm{F}_{1,382.4}=0.86, \mathrm{P}=0.355 ;$ time post-capture, $\mathrm{F}_{1,181.1}=0.087$,

$402 \mathrm{P}=0.768)$ or in initial CORT levels $\left(\mathrm{F}_{1,381.1}=0.17, \mathrm{P}=0.680 ;\right.$ Female mean $3.15 \pm 2.16 \mathrm{ng} / \mathrm{ml}$

403 [SD]; Male mean $3.22 \pm 1.99 \mathrm{ng} / \mathrm{ml}$ ). For jays sampled once under 3 min (all years), sample time

404 post-capture ranged from 45 to $180 \mathrm{sec}(114 \pm 29)$. For jays sampled multiple times under 3 min,

405 time of first sample ranged from 53 to $145 \mathrm{sec}(105 \pm 26)$ and last sample time ranged from 115

406 to $180(166 \pm 18)$. The three SI-CORT categories also did not differ in sample collection time

$407 \quad\left(\mathrm{~F}_{2,381.8}=0.26, \mathrm{P}=0.771 ;\right.$ Low 50 to $180 \mathrm{sec}(118 \pm 29)$, Med 45 to $178 \mathrm{sec}(111 \pm 27)$, High 47

408 to $180 \sec (114 \pm 30)$.

409

\subsection{Change-point}

410

Change-point analysis identified 1.97 min post-capture as the primary change-point when

411 all samples collected under 3 min were analyzed (Table 1). When the data were subdivided by 
412 SI-CORT phenotype, change-points ranged from $1.80 \mathrm{~min}$ to $2.12 \mathrm{~min}$ and did not differ from

413 each other or from the change-point derived for the full dataset (overlapping 95\% confidence

414 intervals; Table 1).

\subsection{Rate of CORT increase}

The rate that CORT increased differed among the three different time periods (initial to 5

$417 \min , 5$ to $15 \mathrm{~min}$, and 15 to $\left.30 \mathrm{~min} ; \mathrm{F}_{2,454}=153, \mathrm{P}<0.0001\right)$. CORT also increased at different

418 rates in jays with different SI-CORT phenotypes $\left(\mathrm{F}_{2,602}=44.2, \mathrm{P}<0.0001\right)$ and there was an

419 interaction between SI-CORT phenotype and time period $\left(\mathrm{F}_{4,454}=10.5, \mathrm{P}<0.0001\right)$. High SI-

420 CORT phenotypes increased more rapidly than Med and Low SI-CORT phenotypes in initial to 4215 min samples ( $\mathrm{P}<0.001$ for both), and again from 5 to $15 \mathrm{~min}$ samples (Low, $\mathrm{P}<0.001$; Med, $422 \mathrm{P}=0.004)$. Med SI-CORT phenotypes increased more rapidly than Low SI-CORT phenotypes

423 from initial to $5 \mathrm{~min}(\mathrm{P}=0.045$; Fig. 1A, B). There was no evidence that Sex affected the rate of 424 CORT change $\left(\mathrm{F}_{1,602}=0.22, \mathrm{P}=0.6386\right)$ and the interaction terms between sex, SI-CORT 425 phenotype, and time period were all statistically non-significant (All P > 0.50). related to SI-CORT phenotype $\left(\mathrm{F}_{2,339.5}=10.49 ; \mathrm{P}<0.0001\right.$, all factors as categorical data in the 429 analysis; Fig. 3A; for SI-CORT and Time as continuous data in the analysis see Table 2A).

430 CORT increased with time post-capture $\left(\mathrm{F}_{3,360.5}=7.53 ; \mathrm{P}<0.0001\right)$ and post hoc analyses 431 indicated that birds sampled prior to $2 \mathrm{~min}(<1.5 \mathrm{~min}$ and $2 \mathrm{~min}$ time points $)$ had lower CORT 432 than those in the 3 min time point $(\mathrm{P}=0.0006, \mathrm{P}<0.0229$, respectively; Fig. $3 \mathrm{~A})$. There was no 433 effect of sex nor were there interactions between sex, sampling time, and SI-CORT phenotype (P $434>0.30)$ 
For data collected in less than 3 min of capture, conditional and marginal $\mathrm{R}_{\mathrm{G}}^{2}$ values for

436 the whole model (all fixed factors) and the three models with single fixed factors are listed in

437 Table 3. Most notable is that marginal and conditional $\mathrm{R}_{\mathrm{G}}^{2}$ values for SI-CORT were similar to

438 those of the whole model, strongly suggesting that SI-CORT was the dominant factor in the

439 whole model and the single best explanatory variable for initial CORT levels. The results from

440 the LMMs for the models with single fixed factors (SI-CORT, $F_{2,289.5}=22.09, \mathrm{P}<0.0001, \beta=$

$441 \quad 0.22 \pm 0.09 ;$ Time, $F_{1,384.2}=12.27, P=0.0005, \beta=0.18 \pm 0.10 ;$ Sex $, F_{1,161.6}=0.16, P=0.689, \beta$

$442=-0.02 \pm 0.10)$ were similar to those of the whole model (Table 2A).

443

444

445

446

447

448

449

450

451

452

453

454

455

456

457

\subsection{Repeated measures of initial CORT}

In birds repeatedly sampled under 3 min, samples were collected on average $0.8 \pm 0.3$

min (mean $\pm \mathrm{SD}$ of $1^{\text {st }}$ to $2^{\text {nd }}$ and $2^{\text {nd }}$ to $3^{\text {rd }}$ ) apart. Sampling time post-capture (all factors as categorical data; $\left.\mathrm{F}_{2,61.8}=6.37 ; \mathrm{P}=0.0031\right)$, SI-CORT phenotype $\left(\mathrm{F}_{3,40.3}=30.11 ; \mathrm{P}<0.0001\right)$, and their interaction $\left(\mathrm{F}_{6,40.1}=3.20 ; \mathrm{P}=0.0116\right)$ influenced initial CORT values (Fig. 3B; for SICORT and Time as continuous data in the analysis, see Table 2B). Post hoc analyses did not detect a significant change in Low SI-CORT phenotype individuals within 3 min of capture (P > 0.05). Within Med SI-CORT birds CORT increased from $<1.5$ to $3 \mathrm{~min}(\mathrm{P}=0.0033)$ and from 2 to $3 \min (\mathrm{P}=0.042)$, but did not differ between the other time points. High SI-CORT birds increased CORT between times 1.5 and $3 \min (P<0.0001), 2$ and $2.5 \min (P=0.0120), 2$ and 3 $\min (\mathrm{P}<0.0001), 2.5$ and $3 \mathrm{~min}(\mathrm{P}=0.0013)$. High SI-CORT birds differed from Low SI-CORT birds at the $<1.5(\mathrm{P}=0.0359), 2.5(\mathrm{P}=0.0038)$, and 3 min time points $(\mathrm{P}=0.0002)$. Med SICORT birds differed from High SI-CORT birds at 3 min $(P=0.0013$; see Fig. 3B).

Repeated sampling of initial CORT did not influence CORT values. Second and third sample values $(n=37)$ collected under 3 min did not differ from the values of jays sampled once 
458 during the same time period $\left(\mathrm{n}=46 ; \mathrm{F}_{1,75}=0.299, \mathrm{P}=0.5861\right)$. As previously seen, initial CORT

459 levels were related to time since capture $\left(\mathrm{F}_{1,75}=15.0, \mathrm{P}=0.0002\right)$ and SI-CORT phenotype $\left(\mathrm{F}_{1,75}\right.$

$460=39.4, \mathrm{P}<0.0001)$, but there were no significant interactions among time since capture, SI-

461 CORT, and sampling method (single vs repeated samples; all $\mathrm{P} \geq 0.8775$ ).

462

\subsection{Initial CORT (under $1.5 \mathrm{~min}$ ) and SI-CORT}

There was a positive relationship between SI-CORT levels and initial CORT levels in

464 samples collected under $1.5 \min \left(2011-2014 ; \mathrm{F}_{1,107.1}=14.56, \mathrm{P}=0.0002, \beta=0.33 \pm 0.17[95 \%\right.$

$465 \mathrm{CI}], \mathrm{n}=113$ ), but there was no effect of sampling time on samples collected between 45 and 90

466 sec post-capture $\left(\mathrm{F}_{1,109}=1.48, \mathrm{P}=0.2262 ; \beta=-0.24 \pm 0.39\right)$ nor was there an interaction

467 between time and SI-CORT $\left(\mathrm{F}_{1,106.3}=2.70, \mathrm{P}=0.1032 ; \beta=0.26 \pm 0.32\right)$. Conditional and

468 marginal $\mathrm{R}_{\mathrm{G}}^{2}$ values for the whole model (all fixed factors) and the two models with single fixed

469 factors on CORT collected under $1.5 \mathrm{~min}$ of capture are listed in Table 3 . The results from the

$470 \mathrm{LMMs}$ for the models with single fixed factors (SI-CORT; $\mathrm{F}_{1,109.1}=13.57, \mathrm{P}=0.0004 ; \beta=0.32$

$471 \pm 0.17$, Fig. 3 ; Time, $F_{1,111}=1.42, P=0.2362 ; \beta=-0.25 \pm 0.41$ ) produced similar results to those

472 of the model containing both fixed factors.

$473 \quad 3.6$ Capture effort

474 Capture effort had no effect on initial CORT values in any of the three analyses, but

475 similar to previous analyses, initial CORT levels in each of the three analyses were influenced by

476 SI-CORT levels (Table 4). Time since capture had an effect on samples collected within 3 min of

477 capture but not samples collected within $1.5 \mathrm{~min}$. Time since capture also did not affect birds

478 captured within 10 min of trapping effort and (sampled within 2 min of capture). 
The primary findings of this study are: 1) on average, jays with higher SI-CORT had

482 higher CORT in samples collected within 1.5 min of capture (i.e., prior to the change-point $95 \%$

483 CIs), suggesting that factors associated with differences in SI-CORT are also associated with

484 baseline CORT levels; 2) plasma CORT began to increase at approximately 2 min post-capture

485 but, based on change-point analysis, the SI-CORT phenotype did not influence the general

486 timing of the increase; 3) starting approximately 2 min post-capture, plasma CORT increased

487 more rapidly in jays with higher SI-CORT phenotypes; 4) the differences in the rate of CORT

488 increase were still detected between 5 and 15 min post-capture but were no longer detectable

489 between 15 and 30 min post-capture, and 5) there was no evidence that pre-capture interactions

490 with the trap, or observing other jays being trapped, influenced CORT values.

\subsection{Baseline CORT}

The correlation between SI-CORT and initial CORT levels collected before the CORT

493 change-point supports the hypothesis that baseline (i.e., pre-capture) CORT regulation is

494 influenced by the general stress response phenotype in Florida scrub-jays. Based on the linear

495 relationship between initial CORT values collected $<1.5 \mathrm{~min}$ of capture and SI-CORT levels, the

496 most stress-responsive jays have baseline CORT values that are, on average, approximately two

497 or more times higher than the least stress-responsive jays (Fig. 4). However, the marginal $\mathrm{R}^{2}{ }_{\mathrm{G}}$ for

498 the $<1.5 \mathrm{~min}$ SI-CORT model (Table 4) indicates that SI-CORT only accounts for

499 approximately $11 \%$ of the variation in the CORT values. Visual inspection of Figure 4 also

500 highlights the considerable variability in initial CORT concentrations among individuals with

501 similar SI-CORT phenotypes. Taken together, these data suggest that the factors responsible for

502 inter-individual differences in SI-CORT levels also influence baseline CORT regulation in 
503 Florida scrub-jays. However, this effect at baseline levels, prior to the influence of capture and

504 handling stress, does not appear to overshadow the influence of other factors.

506 concentrations are correlated in Florida scrub-jays or whether this is a common phenomenon in

507 other species. It is possible that this phenomenon is exclusively found in species with long-term,

508 repeatable phenotypic differences in stress-responsiveness. Inter-individual differences in stress-

509 responsiveness have been shown to covary with a variety of persistent behavioral and

510 physiological traits that may have different energetic requirements (see Cockrem, 2013b;

511 Schoech et al., 2011 for reviews). These suites of covarying traits are often called behavioral

512 types, personalities, or behavioral syndromes, and individuals are commonly ranked on a "bold-

513 shy," "reactive-proactive," or "fast-slow" continuum (for reviews see Carter et al., 2013; Dall et

514 al., 2012; Dall and Griffith, 2014; Sih et al., 2012; Sih and Del Giudice, 2012). Individuals on the

515 bold, proactive, and fast end of the spectrum are hypothesized to have a faster "pace-of-life" that

516 requires higher CORT levels to support their more energetically demanding life-style (Careau

517 and Garland, 2012; Carere et al., 2010). There is evidence that a similar relationship between SI-

518 CORT phenotype and behavior exists in Florida scrub-jays, with lower SI-CORT jays being

519 "bolder" and more "proactive" than higher SI-CORT jays (Bebus et al., 2013; Jones et al., 2013).

520 However, the relationship between baseline CORT levels and bold/proactive behavior in Florida

521 scrub-jays is in the opposite direction of what is commonly predicted by the "pace-of-life"

522 hypothesis. The "bolder", lower SI-CORT jays have lower baseline CORT, not the higher levels

523 that would support their presumed faster lifestyle. This potential contradiction does not exclude

524 the possibility that differences in behaviors or energetic needs are driving differences in baseline

525 CORT, as similar relationships between lower baseline CORT and "faster" life histories have 
526 been observed (Palacios et al., 2012; Versteegh et al., 2012). If higher SI-CORT jays do have

527 higher energetic requirements that cause, or are caused by elevated baseline CORT levels, those

528 behaviors and metabolic processes remain unclear.

$529 \quad$ Understanding how inter-individual differences in stress-responsiveness are regulated 530 could provide important insight into why baseline and SI-CORT levels covary. The differences

531 could be regulated at the level of the adrenal gland, further up the HPA axis, in the cognitive

532 processing of environmental stimuli, or a combination of these factors (Herman et al., 2003;

$533 \varnothing v e r l i$ et al., 2007). In a wide variety of vertebrates, differences in stress-responsiveness are

534 associated with differences in adrenal sensitivity to ACTH (Carsia and John-Alder, 2003; Ingram

535 et al., 1999; King et al., 1993; Michopoulos et al., 2012; Singh et al., 1999; Slawik et al., 2004;

536 Veenema et al., 2004), and adrenal production of CORT (Heidinger et al., 2008; Romero et al.,

537 1998; Romero and Wingfield, 1998). Differences in the general functioning of the HPA axis

538 during an acute, extreme stressor could also influence CORT regulation at or near baseline levels

539 (Veenema et al., 2004). In such a case, the observed correlation between baseline and SI-CORT

540 levels in Florida scrub-jays could simply be due to a functional difference in the HPA axis of an

541 individual that consistently influences CORT production throughout the entirety of CORT's

542 concentration range.

543 Despite the covariance of baseline and SI-CORT concentrations, these inter-individual

544 differences may not result in physiologically meaningful effects at both low and high CORT

545 concentrations. The effects of CORT at baseline levels are primarily regulated through high-

546 affinity mineralocorticoid receptors, while the effects of SI-CORT are largely mediated through

547 low-affinity glucocorticoid receptors (Funder, 1997; Landys et al., 2006). Individual differences

548 in stress-responsiveness may be accompanied by differential regulation of these receptor types, 
549 or their downstream signaling pathways (Lattin et al., 2015; Lattin and Romero, 2013). If this is

550 the case in Florida scrub-jays, higher concentrations of mineralocorticoid receptors in lower SI-

551 CORT jays could compensate for their, on average, lower baseline CORT levels and render the

552 phenotypic differences in baseline CORT physiologically meaningless (i.e., high SI-CORT jays

553 require higher baseline CORT levels to elicit the same physiological response as lower baseline

554 levels elicit in low SI-CORT jays). At the same time, an absence of differences in glucocorticoid

555 receptor concentrations across different stress-responsive phenotypes would allow for the

556 differences in SI-CORT concentrations to have different physiological and behavioral effects in

557 the jays. Similarly, higher corticosteroid binding globulin (CBGs; Breuner and Orchinik, 2002)

558 in higher stress-responsiveness individuals could result in similar "free-CORT" concentrations

559 across stress-responsive phenotypes despite there being differences in total baseline CORT

560 levels; however, we are unaware of any studies to date that have identified differences in CBGs

561 associated with differences in behavioral or stress-responsive phenotypes (Malisch et al., 2010,

562 2008). More work is needed to understand if these differences in plasma CORT regulation are

563 accompanied by differences in tissue sensitivity to CORT.

4.2 SI-CORT phenotype and rate of CORT increase during initial sampling

Our results also support the hypothesis that differences in stress-responsiveness are

566 reflected in the rate at which CORT increases during the 3 min post-capture sampling period.

567 The changes in CORT concentration between 2 and 3 min post-capture mirrored the differences

568 in the rate CORT increased between initial sample collection and 5 min post-capture, and again

569 between 5 and 15 min (Fig. 1B, 3). Between 2 and 3 min post-capture, CORT increased 2-3

570 times more in high SI-CORT phenotype jays (approx. $2.6 \mathrm{ng} / \mathrm{ml}$ averaged between single- and

571 repeated-measure studies) compared to low SI-CORT birds $(0.9 \mathrm{ng} / \mathrm{ml}$ increase; not a 
572 statistically significant increase). Combined with the differences in baseline CORT that existed

573 before CORT began to rise, high SI-CORT jays had CORT concentrations between 2.5 and 3

574 min that were nearly twice that of the low SI-CORT jays (see Fig. 3). It could be argued that the

575 general increase in CORT during the initial sampling period does more to exaggerate the pre-

576 capture differences in baseline CORT rather than obscure those differences. However, this

577 argument assumes that all post-capture samples are collected in a very narrow window of time.

578 Instead, once CORT begins to rise, as little as a $30 \mathrm{sec}$ difference in sampling time could produce

579 large differences in CORT values between individuals that previous had little or no differences in

580 CORT (Fig. 2B). Correcting for such a time effect would be difficult and, at the very least,

581 would require knowledge of individual differences in SI-CORT and an estimate of the CORT

582 change point.

Although it remains to be determined whether a similar phenomenon occurs in other

584 species, there are reasons to think it is common. Differences in stress-responsiveness are well

585 documented throughout vertebrates (Breuner et al., 2008; Cockrem, 2013a; Hing et al., 2014;

586 Øverli et al., 2007) and, in comparison to other species studied, Florida scrub-jays have moderate

587 to low inter-individual variation in SI-CORT levels. Cockrem (2013a) calculated the coefficient

588 of variation (CV) for SI-CORT within 66 species of fish, amphibians, reptiles, birds, and

589 mammals and found the average within species SI-CORT CV (initial sample to $30 \mathrm{~min}$ ) to be

$590 \quad 53.1 \%$ (48.6\% in birds), compared to $35.8 \%$ for the Florida scrub-jays in this study (250/698

$591 \mathrm{ng} / \mathrm{ml}[\mathrm{SD} / \mathrm{mean}])$. These data suggest that once CORT begins to increase in a species with

592 individual differences in stress-responsiveness, SI-CORT values will diverge at a rate that is

593 similar or faster than what occurs in Florida scrub-jays.

594 CORT is likely to increase within 3 min of an acute stressor in many animals. Based on 
studies by Romero and Reed (2005) and others (Beuving and Vonder, 1978; Dawson, 1983;

596 Harvey et al., 1980; Heidinger et al., 2006; Maho et al., 1992; Schwabl et al., 1991), most species

597 of birds that have been closely studied have a CORT change-point of 2 min or less during much

598 of their annual cycle. Although far less is known about the exact time CORT begins to increase

599 in other types of free-living animals, many mammals, and in some circumstances reptiles and

600 fish, share a similar rapid increase in CORT that reaches peak, or near peak, levels within 10-15

601 min of the initiation of a stressor (Baker et al., 2013; Cartledge and Jones, 2007; Cockrem,

602 2013a; Reeder and Kramer, 2005; Romero and Wikelski, 2001). In these cases, the initiation of a

603 rise in CORT levels (change-point) may occur at a similar time point to that of many birds.

Given the potential prevalence of this phenomenon, it is surprising that correlations

605 between SI-CORT and CORT sampled within 3 min of capture are not reported more often (but

606 see Baugh et al., 2014; Deviche et al., 2014; Malisch et al., 2013; Vitousek et al., 2014).

607 However, baseline CORT levels can rapidly change in response to recent experiences, such as

608 the amount of physical activity (Girard and Garland, 2002; Mastorakos et al., 2005; Rees et al.,

609 1985; Rees and Harvey, 1987), encounters with con- or hetero-specific individuals (Jones et al.,

610 2016; Ros et al., 2014; Van Duyse et al., 2004), and the fed state of the animal (Fokidis et al.,

611 2012; Herring and Gawlik, 2013; Kitaysky et al., 1999). Because of this, individual variation in

612 experience in the minutes to hours prior to sample collection could obscure longer-term patterns

613 (e.g., days to weeks) in baseline CORT levels (Landys et al., 2006). We investigated whether our

614 use of walk-in baited traps to catch jays provided a "standardized" experience prior to capture

615 that made the effect of stress-responsiveness on baseline values more easily detectable.

616 However, there was no effect of the amount of time a jay spent interacting with the trap prior to

617 capture (capture effort) and initial CORT values. Additionally, we found a strong correlation 
618 between initial CORT (sampled within 2 min of capture) and SI-CORT in jays caught within 10

619 min of setting out the trap. Together these data suggest that the trapping protocol either had no

620 effect on baseline CORT levels or it influenced baseline CORT within a few minutes of

621 exposure, and the effect did not increase over time.

622 Another explanation for why a correlation between initial and SI-CORT values exists in

623 Florida scrub-jays, but is less commonly observed in other species, is that the jays were always

624 sampled during the pre- to early-breeding season (sampling occurred on average $48 \pm 17$ days

$625[\mathrm{SD}]$ prior to clutch initiation by the breeder female of a given group), a period when baseline

626 CORT levels may be less responsive to environmental factors. Some animals dampen HPA axis

627 responsiveness throughout the breeding period to prevent elevated CORT levels from adversely

628 affecting reproductive activities, such as egg production and parental care (Angelier and Chastel,

629 2009; Ouyang et al., 2012; Pitk et al., 2012; Saino et al., 2005; Schoech et al., 2012). Under these

630 conditions, broader phenotypic differences might be easier to detect. Consistent with this idea,

631 Florida scrub-jay SI-CORT levels measured during this same time period are highly repeatable

632 among years and initial CORT values are repeatable among years in males (Small and Schoech, 633 2015).

Our findings raise concerns about the measurement and interpretation of baseline CORT values when stress-responsiveness varies among individuals. When CORT begins to rise during

637 the initial sampling period, it cannot be assumed that the changes are small and similar among

638 individuals (Fig. 2B). The overall increase in CORT levels between 2-3 min post-capture

639 accounts for less than $10 \%$ of the variance in the data (comparing marginal $\mathrm{R}_{\mathrm{G}}^{2}$ for time $<1.5$

640 and $<3 \mathrm{~min}$; Table 3 ). This relatively small impact is consistent with the previous observations 
641 by Romero and Reed (2005) that samples collected within 3 min of capture are "near baseline".

642 However, the concern does not specifically arise from the amount of additional variance added to

643 the entire data set; instead, the primary concern is that the impact of time since capture on CORT

644 values is both unevenly and non-randomly distributed (Figs. 2-4). Most of the variance due to

645 time since capture is from the $27 \%$ of samples collected between 2 and 3 min post-capture (see

646 sample sizes Fig. 3A), and within that 27\% subset, individuals with higher SI-CORT phenotypes

647 are responsible for a larger proportion of the increase in CORT (Fig. 2B).

648 If differences in stress-responsiveness are unrelated to the independent variable under

649 investigation, this uneven, non-random increase in CORT may only decrease the likelihood of

650 detecting differences in baseline values. However, stress-responsiveness is known to vary with

651 numerous intrinsic and extrinsic factors (Baker et al., 2013; Crespi et al., 2013), such as life-

652 history stage (Romero, 2002; Romero et al., 2008; Wingfield et al., 1992), fluctuating weather

653 conditions (Romero et al., 2000; Rubenstein, 2007), social status (Cavigelli and Chaudhry, 2012;

654 Creel et al., 2013; Summers et al., 2005), age (Elliott et al., 2014; Heidinger et al., 2010),

655 resource availability (Schoech et al., 2007), habitat characteristics (Bauer et al., 2013; Fokidis et

656 al., 2009; Li et al., 2011; Lucas and French, 2012), and reproductive effort and success (Lendvai

657 and Chastel, 2010; Miller et al., 2009; Schmid et al., 2013; Vitousek et al., 2014). Many of these

658 same factors are also associated with differences in baseline CORT (Baker et al., 2013; Bonier et

659 al., 2009). When differences in stress-responsiveness are unevenly distributed among the groups

660 being compared, as would be expected in the above cited examples, the differences in capture-

661 and-handling time along with the phenotypic differences in rates of CORT increase could

662 obscure or supersede moderate pre-capture differences in baseline CORT levels. The work of

663 Baugh et al. (2013) on great tits clearly demonstrates that just such an error could occur if stress- 
664 responsiveness and the timing the rise of CORT are not considered. If such errors are common,

665 they could explain some of the contradictory results found in the baseline CORT literature

666 (Bonier et al., 2009; Crespi et al., 2013; Dickens and Romero, 2013).

In Florida scrub-jays, an individual's stress response phenotype appears to influence

670 measures of baseline CORT in two important ways. First, what we consider to be "true" baseline

671 CORT concentrations (collected within 1.5 min of capture) mirror an individual's stress response

672 phenotype, with higher SI-CORT jays having, on average, higher baseline CORT concentrations.

673 The reason this connection exists is presently unknown but the among individual differences

674 related to SI-CORT are small enough as to not obscure moderate to large differences in CORT

675 caused by other factors. However, knowledge of an individual's stress response phenotype may

676 be important for understanding what differences in baseline values mean for these animals.

677 Second, differences in stress response phenotypes are primarily driven by differences in the rate

678 at which CORT increases in the first few minutes of an extreme stressor, such as capture and

679 handling. Once CORT begins to increase at about 2 min post-capture, the phenotypic differences

680 in rates of increase complicate any attempt to determine pre-capture CORT levels (i.e., "true"

681 baseline), not to mention its links with any number of potential variables of interest (e.g., fitness,

682 health, reproduction, etc.).

684 jays, plasma CORT "samples collected in less than 2 min can be assumed to reflect unstressed

685 concentrations with a high degree of confidence", and samples collected within 3 min are "near

686 enough to baseline to be distinguishable from stress-induced concentrations". However, in 
687 Florida scrub-jays, it cannot be assumed that samples collected between 2 and 3 min accurately

688 represent pre-capture differences in CORT levels. This phenomenon does not appear to be

689 unique to Florida scrub-jays (Baugh et al., 2013), but it is presently unknown how common it is.

690 We do not believe that these results indicate that an under 2 min post-capture sampling

691 limit should be broadly adopted, as it may be unnecessarily restrictive. We also do not believe

692 that sampling after the post-capture rise in CORT begins will always produce inaccurate

693 estimates of among individual differences in baseline CORT. Instead, we recommend that at the

694 very least, studies report the range and mean \pm standard deviation of sampling times for each

695 group being compared (e.g., each life history stage, social status level, habitat type, etc.), instead

696 of only reporting the maximum sampling time for all samples collected (e.g., $<3 \mathrm{~min}$ ). With this

697 information, sample collection time can be taken into consideration when comparing results

698 across studies.

We also recommend validating if CORT increases during the baseline sampling period,

700 the magnitude of any changes that do exist, and if there are inter-individual differences in the

701 rate of change. Ideally, this should be done for each group being compared within a study to

702 determine if differences exist among groups that could obscure or bias the results. When more

703 than one blood sample can be safely collected from a subject, we encourage validating the timing

704 of CORT sample collection using a repeated measures design. In this study, the repeated

705 measures analysis of samples collected under 3 min contained less than one tenth as many

706 subjects as the independent measures analysis, yet it still produced highly robust results (Table

707 2). In many studies, a small subset of subjects could be repeatedly sampled during the initial

708 sampling period with few or no modifications to the experimental protocol, and for little

709 additional cost. Even with small sample sizes, and no measure of stress-induced CORT, visual 
710 inspection of repeated measures baseline CORT data (Fig. 2B) could provide important insight

711 into the dynamics of, and inter-individual variation in, the rise of CORT during the initial

712 sampling period. Armed with this information, researchers should be better able to determine the

713 most appropriate baseline CORT sampling protocol for their study system.

714

715

\section{Acknowledgments}

716 We thank our hosts at Archbold Biological Station, Drs. R. Bowman and H. Swain, as

717 well as the many other individuals who facilitate the smooth running of the station. We would

718 also like to thank Dr. Rebecca Heiss for her help collecting blood samples and Dr. Michael

719 Romero for comments on an early version of the manuscript. Finally, we would like to thank

720 three anonymous reviewers for their comments and assistance with this manuscript. Financial

721 support was provided by the National Science Foundation of the US (IOS-0919899 to SJS and

722 ESB: TWS was supported in part by this grant), as well as the Department of Biological Sciences

723 at the University of Memphis.

724

725

726

727

728

729 References: 
Andersen, T., Carstensen, J., Hernández-García, E., Duarte, C.M., 2009. Ecological thresholds and regime shifts: approaches to identification. Trends Ecol. Evol. 24, 49-57. doi:10.1016/j.tree.2008.07.014

Angelier, F., Chastel, O., 2009. Stress, prolactin and parental investment in birds: a review. Gen. Comp. Endocrinol. 163, 142-148. doi:10.1016/j.ygcen.2009.03.028

Atkinson, H.C., Wood, S.A., Castrique, E.S., Kershaw, Y.M., Wiles, C.C.R., Lightman, S.L., 2008. Corticosteroids mediate fast feedback of the rat hypothalamic-pituitary-adrenal axis via the mineralocorticoid receptor. Am. J. Physiol. - Endocrinol. Metab. 294, E1011E1022. doi:10.1152/ajpendo.00721.2007

Awata, S., Tsuruta, T., Yada, T., Iguchi, K., 2011. Effects of suspended sediment on cortisol levels in wild and cultured strains of ayu Plecoglossus altivelis. Aquaculture 314, 115121. doi:10.1016/j.aquaculture.2011.01.024

Baker, M.R., Gobush, K.S., Vynne, C.H., 2013. Review of factors influencing stress hormones in fish and wildlife. J. Nat. Conserv. 21, 309-318. doi:10.1016/j.jnc.2013.03.003

Bauer, C.M., Skaff, N.K., Bernard, A.B., Trevino, J.M., Ho, J.M., Romero, L.M., Ebensperger, L.A., Hayes, L.D., 2013. Habitat type influences endocrine stress response in the degu (Octodon degus). Gen. Comp. Endocrinol. 186, 136144.doi:10.1016/j.ygcen.2013.02.036

Baugh, A.T., van Oers, K., Dingemanse, N.J., Hau, M., 2014. Baseline and stress-induced glucocorticoid concentrations are not repeatable but covary within individual great tits (Parus major). Gen. Comp. Endocrinol. 208, 154-163. doi:10.1016/j.ygcen.2014.08.014

Baugh, A.T., van Oers, K., Naguib, M., Hau, M., 2013. Initial reactivity and magnitude of the acute stress response associated with personality in wild great tits (Parus major). Gen. Comp. Endocrinol. 189, 96-104. doi:10.1016/j.ygcen.2013.04.030

Bebus, S.E., Small, T.W., Schoech, S.J., 2013. Developmental corticosterone exposure is correlated with exploratory behavior and learning flexibility in Florida scrub-jays (Aphelocoma coerulescens). Integr. Comp. Biol. 53, E12.

Beuving, G., Vonder, G.M.A., 1978. Effect of stressing factors on corticosterone levels in the plasma of laying hens. Gen. Comp. Endocrinol. 35, 153-159. doi:10.1016/00166480(78)90157-0

Bonier, F., Martin, P.R., Moore, I.T., Wingfield, J.C., 2009. Do baseline glucocorticoids predict fitness? Trends Ecol. Evol. 24, 634-642. doi:10.1016/j.tree.2009.04.013

Boonstra, R., 2005. Equipped for life: The adaptive role of the stress axis in male mammals. J. Mammal. 86, 236-247. doi:10.1644/BHE-001.1

Breuner, C.W., Orchinik, M., 2002. Plasma binding proteins as mediators of corticosteroid action in vertebrates. J. Endocrinol. 175, 99-112. doi:10.1677/joe.0.1750099

Breuner, C.W., Patterson, S.H., Hahn, T.P., 2008. In search of relationships between the acute adrenocortical response and fitness. Gen. Comp. Endocrinol. 157, 288-295. doi:10.1016/j.ygcen.2008.05.017

Careau, V., Garland, T., 2012. Performance, personality, and energetics: correlation, causation, and mechanism. Physiol. Biochem. Zool. 85, 543-571. doi:10.1086/666970

Carere, C., Caramaschi, D., Fawcett, T., 2010. Covariation between personalities and individual differences in coping with stress: converging evidence and hypotheses. Curr. Zool. 56, $728-740$. 
Carpenter, L.L., Carvalho, J.P., Tyrka, A.R., Wier, L.M., Mello, A.F., Mello, M.F., Anderson, G.M., Wilkinson, C.W., Price, L.H., 2007. Decreased adrenocorticotropic hormone and cortisol responses to stress in healthy adults reporting significant childhood maltreatment. Biol. Psychiatry 62, 1080-1087. doi:10.1016/j.biopsych.2007.05.002

Carsia, R.V., John-Alder, H., 2003. Seasonal alterations in adrenocortical cell function associated with stress-responsiveness and sex in the eastern fence lizard (Sceloporus undulatus). Horm. Behav. 43, 408-420. doi:10.1016/S0018-506X(03)00013-8

Carter, A.J., Marshall, H.H., Heinsohn, R., Cowlishaw, G., 2013. Personality predicts decision making only when information is unreliable. Anim. Behav. 86, 633639.doi:10.1016/j.anbehav.2013.07.009

Cartledge, V.A., Jones, S.M., 2007. Does adrenal responsiveness vary with sex and reproductive status in Egernia whitii, a viviparous skink? Gen. Comp. Endocrinol. 150, 132-139. doi:10.1016/j.ygcen.2006.07.021

Cavigelli, S.A., Chaudhry, H.S., 2012. Social status, glucocorticoids, immune function, and health: Can animal studies help us understand human socioeconomic-status-related health disparities? Horm. Behav. 62, 295-313. doi:10.1016/j.yhbeh.2012.07.006

Claessens, S.E.F., Daskalakis, N.P., van der Veen, R., Oitzl, M.S., de Kloet, E.R., Champagne, D.L., 2011. Development of individual differences in stress responsiveness: an overview of factors mediating the outcome of early life experiences. Psychopharmacology (Berl.) 214, 141-154. doi:10.1007/s00213-010-2118-y

Cockrem, J.F., 2013a. Individual variation in glucocorticoid stress responses in animals. Gen. Comp. Endocrinol. 181, 45-58. doi:10.1016/j.ygcen.2012.11.025

Cockrem, J.F., 2013b. Corticosterone responses and personality in birds: Individual variation and the ability to cope with environmental changes due to climate change. Gen. Comp. Endocrinol. 190, 156-163. doi:10.1016/j.ygcen.2013.02.021

Cockrem, J.F., Silverin, B., 2002. Variation within and between birds in corticosterone responses of great tits (Parus major). Gen. Comp. Endocrinol. 125, 197-206.

Cook, K.V., O’Connor, C.M., Gilmour, K.M., Cooke, S.J., 2011. The glucocorticoid stress response is repeatable between years in a wild teleost fish. J. Comp. Physiol. A 197, 1189-1196. doi:10.1007/s00359-011-0680-3

Creel, S., Dantzer, B., Goymann, W., Rubenstein, D.R., 2013. The ecology of stress: effects of the social environment. Funct. Ecol. 27, 66-80. doi:10.1111/j.1365-2435.2012.02029.x

Crespi, E.J., Williams, T.D., Jessop, T.S., Delehanty, B., 2013. Life history and the ecology of stress: how do glucocorticoid hormones influence life-history variation in animals? Funct. Ecol. 27, 93-106. doi:10.1111/1365-2435.12009

Dall, S.R.X., Bell, A.M., Bolnick, D.I., Ratnieks, F.L.W., Sih, A., 2012. An evolutionary ecology of individual differences. Ecol. Lett. 15, 1189-1198. doi:10.1111/j.14610248.2012.01846.x

Dall, S.R.X., Griffith, S.C., 2014. An empiricist guide to animal personality variation in ecology and evolution. Front. Ecol. Evol. 2, 1-7. doi:10.3389/fevo.2014.00003

Dallman, M.F., Bhatnagar, S., 2001. Chronic stress and energy balance: role of the hypothalamopituitary-adrenal axis, in: Terjung, R. (Ed.), Handbook of Physiology, The Endocrine System, Coping with the Environment: Neural and Endocrine Mechanisms. John Wiley \& Sons, Inc., Hoboken, NJ, USA, pp. 179-210. doi:10.1002/cphy.cp070410 
Dawson, A., 1983. Plasma gonadal steroid levels in wild starlings (Sturnus vulgaris) during the annual cycle and in relation to the stages of breeding. Gen. Comp. Endocrinol. 49, 286294.

Deviche, P., Beouche-Helias, B., Davies, S., Gao, S., Lane, S., Valle, S., 2014. Regulation of plasma testosterone, corticosterone, and metabolites in response to stress, reproductive stage, and social challenges in a desert male songbird. Gen. Comp. Endocrinol. 203, 120131. doi: 10.1016/j.ygcen.2014.01.010

Dickens, M.J., Romero, L.M., 2013. A consensus endocrine profile for chronically stressed wild animals does not exist. Gen. Comp. Endocrinol. 191, 177-189. doi:10.1016/j.ygcen.2013.06.014

Douxfils, J., Mandiki, S.N.M., Marotte, G., Wang, N., Silvestre, F., Milla, S., Henrotte, E., Vandecan, M., Rougeot, C., Mélard, C., Kestemont, P., 2011. Does domestication process affect stress response in juvenile Eurasian perch Perca fluviatilis? Comp. Biochem. Physiol. A. Mol. Integr. Physiol. 159, 92-99. doi:10.1016/j.cbpa.2011.01.021

Elliott, K.H., O'Reilly, K.M., Hatch, S.A., Gaston, A.J., Hare, J.F., Anderson, W.G., 2014. The prudent parent meets old age: a high stress response in very old seabirds supports the terminal restraint hypothesis. Horm. Behav. 66, 828-837. doi:10.1016/j.yhbeh.2014.11.001

Ericsson, M., Fallahsharoudi, A., Bergquist, J., Kushnir, M.M., Jensen, P., 2014. Domestication effects on behavioural and hormonal responses to acute stress in chickens. Physiol. Behav. 133, 161-169. doi:10.1016/j.physbeh.2014.05.024

Fokidis, H.B., des Roziers, M.B., Sparr, R., Rogowski, C., Sweazea, K., Deviche, P., 2012. Unpredictable food availability induces metabolic and hormonal changes independent of food intake in a sedentary songbird. J. Exp. Biol. 215, 2920-2930. doi:10.1242/jeb.071043

Fokidis, H.B., Orchinik, M., Deviche, P., 2009. Corticosterone and corticosteroid binding globulin in birds: relation to urbanization in a desert city. Gen. Comp. Endocrinol. 160, 259-270. doi:10.1016/j.ygcen.2008.12.005

Funder, J.W., 1997. Glucocorticoid and mineralocorticoid receptors: biology and clinical relevance. Annu. Rev. Med. 48, 231-240. doi:10.1146/annurev.med.48.1.231

Girard, I., Garland, T., 2002. Plasma corticosterone response to acute and chronic voluntary exercise in female house mice. J. Appl. Physiol. 92, 1553-1561.

Harvey, S., Merry, B.J., Phillips, J.G., 1980. Influence of stress on the secretion of corticosterone in the duck (Anas platyrhynchos). J. Endocrinol. 87, 161-171.

Hau, M., Goymann, W., 2015. Endocrine mechanisms, behavioral phenotypes and plasticity: known relationships and open questions. Front. Zool. 12, S7. doi:10.1186/1742-9994-12S1-S7

Heidinger, B.J., Chastel, O., Nisbet, I.C.T., Ketterson, E.D., 2010. Mellowing with age: older parents are less responsive to a stressor in a long-lived seabird. Funct. Ecol. 24, 10371044. doi:10.1111/j.1365-2435.2010.01733.x

Heidinger, B.J., Nisbet, I.C.T., Ketterson, E.D., 2008. Changes in adrenal capacity contribute to a decline in the stress response with age in a long-lived seabird. Gen. Comp. Endocrinol. 156, 564-568. doi:10.1016/j.ygcen.2008.02.014

Heidinger, B.J., Nisbet, I.C.T., Ketterson, E.D., 2006. Older parents are less responsive to a stressor in a long-lived seabird: a mechanism for increased reproductive performance with age? Proc. R. Soc. Lond. B Biol. Sci. 273, 2227-2231. doi:10.1098/rspb.2006.3557 
Herman, J.P., Figueiredo, H., Mueller, N.K., Ulrich-Lai, Y., Ostrander, M.M., Choi, D.C., Cullinan, W.E., 2003. Central mechanisms of stress integration: hierarchical circuitry controlling hypothalamo-pituitary-adrenocortical responsiveness. Front. Neuroendocrinol. 24, 151-180. doi:10.1016/j.yfrne.2003.07.001

Herring, G., Gawlik, D.E., 2013. Differential physiological responses to prey availability by the great egret and white ibis. J. Wildl. Manag. 77, 58-67. doi:10.1002/jwmg.445

Hing, S., Narayan, E., Thompson, R.C.A., Godfrey, S., 2014. A review of factors influencing the stress response in Australian marsupials. Conserv. Physiol. 2, cou027. doi:10.1093/conphys/cou027

Hinkley, D., Schechtman, E., 1987. Conditional bootstrap methods in the mean-shift model. Biometrika 74, 85-93. doi:10.2307/2336023

Homberger, B., Jenni-Eiermann, S., Jenni, L., 2015. Distinct responses of baseline and stressinduced corticosterone levels to genetic and environmental factors. Gen. Comp. Endocrinol. 210, 46-54. doi:10.1016/j.ygcen.2014.09.020

Hruschka, D.J., Kohrt, B.A., Worthman, C.M., 2005. Estimating between- and within-individual variation in cortisol levels using multilevel models. Psychoneuroendocrinology 30, 698714. doi:10.1016/j.psyneuen.2005.03.002

Ingram, J.R., Crockford, J.N., Matthews, L.R., 1999. Ultradian, circadian and seasonal rhythms in cortisol secretion and adrenal responsiveness to ACTH and yarding in unrestrained red deer (Cervus elaphus) stags. J. Endocrinol. 162, 289-300. doi:10.1677/joe.0.1620289

Johnstone, C.P., Reina, R.D., Lill, A., 2012. Interpreting indices of physiological stress in freeliving vertebrates. J. Comp. Physiol. [B] 182, 861-879. doi:10.1007/s00360-012-0656-9

Jones, B.C., Bebus, S.E., Small, T.W., Bateman, P.W., Schoech, S.J., 2013. Corticosterone responsiveness and behavioral phenotype reveal learned antipredator behavior is sex specific in Florida scrub-jays (Aphelocoma coerulescens). Integr. Comp. Biol. 53, E104.

Jones, B.C., Smith, A.D., Bebus, S.E., Schoech, S.J., 2016. Two seconds is all it takes: European starlings (Sturnus vulgaris) increase levels of circulating glucocorticoids after witnessing a very brief raptor attack. Horm. Behav. 78, 157-168. doi:10.1016/j.yhbeh.2015.10.017

King, J.A., Campbell, D., Edwards, E., 1993. Differential development of the stress response in congenital learned helplessness. Int. J. Dev. Neurosci. 11, 435-442. doi:10.1016/07365748(93)90017-8

Kitaysky, A.S., Wingfield, J.C., Piatt, J.F., 1999. Dynamics of food availability, body condition and physiological stress response in breeding black-legged kittiwakes. Funct. Ecol. 13, 577-584. doi:10.1046/j.1365-2435.1999.00352.x

Koolhaas, J.M., Korte, S.M., De Boer, S.F., Van Der Vegt, B.J., Van Reenen, C.G., Hopster, H., De Jong, I.C., Ruis, M.A.W., Blokhuis, H.J., 1999. Coping styles in animals: current status in behavior and stress-physiology. Neurosci. Biobehav. Rev. 23, 925-935.

Künzl, C., Sachser, N., 1999. The behavioral endocrinology of domestication: a comparison between the domestic guinea pig (Cavia apereaf. porcellus) and its wild ancestor, the cavy (Cavia aperea). Horm. Behav. 35, 28-37.

Landys, M.M., Ramenofsky, M., Wingfield, J.C., 2006. Actions of glucocorticoids at a seasonal baseline as compared to stress-related levels in the regulation of periodic life processes. Gen. Comp. Endocrinol. 148, 132-149. doi:10.1016/j.ygcen.2006.02.013

Lattin, C.R., Keniston, D.E., Reed, J.M., Romero, L.M., 2015. Are receptor concentrations correlated across tissues within individuals? A case study examining glucocorticoid and 
952

953

954

955

mineralocorticoid receptor binding. Endocrinology 156, 1354-1361.

doi:10.1210/en.2014-1811

Lattin, C.R., Romero, L.M., 2013. Seasonal variation in corticosterone receptor binding in brain, hippocampus, and gonads in House Sparrows (Passer domesticus). The Auk 130, 591598. doi:10.1525/auk.2013.13043

Lefcheck, J.S., 2015. piecewiseSEM: Piecewise structural equation modeling in R for ecology, evolution, and systematics. arXiv:150901845 [q-bioQM].

Lendvai, A.Z., Chastel, O., 2010. Natural variation in stress response is related to post-stress parental effort in male house sparrows. Horm. Behav. 58, 936-942. doi:10.1016/j.yhbeh.2010.09.004

Li, D., Wu, J., Zhang, X., Ma, X., Wingfield, J.C., Lei, F., Wang, G., Wu, Y., 2011. Comparison of adrenocortical responses to acute stress in lowland and highland Eurasian tree sparrows (Passer montanus): similar patterns during the breeding, but different during the prebasic molt. J. Exp. Zool. Part A Ecol. Genet. Physiol. 315, 512-519. doi:10.1002/jez.699

Lucas, L.D., French, S.S., 2012. Stress-induced tradeoffs in a free-living lizard across a variable landscape: consequences for individuals and populations. PloS One 7, e49895. doi:10.1371/journal.pone.0049895

Maho, Y.L., Karmann, H., Briot, D., Handrich, Y., Robin, J.P., Mioskowski, E., Cherel, Y., Farni, J., 1992. Stress in birds due to routine handling and a technique to avoid it. Am. J. Physiol. - Regul. Integr. Comp. Physiol. 263, R775-R781.

Malisch, J.L., Breuner, C.W., Gomes, F.R., Chappell, M.A., Garland, T., 2008. Circadian pattern of total and free corticosterone concentrations, corticosteroid-binding globulin, and physical activity in mice selectively bred for high voluntary wheel-running behavior. Gen. Comp. Endocrinol. 156, 210-7. doi:10.1016/j.ygcen.2008.01.020

Malisch, J.L., Satterlee, D.G., Cockrem, J.F., Wada, H., Breuner, C.W., 2010. How acute is the acute stress response? Baseline corticosterone and corticosteroid-binding globulin levels change $24 \mathrm{~h}$ after an acute stressor in Japanese quail. Gen. Comp. Endocrinol. 165, 345350. doi:10.1016/j.ygcen.2009.08.003

Malisch, J.L., Saltzman, W., Gomes, F.R., Rezende, E.L., Jeske, D.R., Garland, T., 2013. Baseline and stress-induced plasma corticosterone concentrations of mice selectively bred for high voluntary wheel running. Physiol. Biochem. Zool. 80, 146-156. doi:10.1086/508828

Mastorakos, G., Pavlatou, M., Diamanti-Kandarakis, E., Chrousos, G.P., 2005. Exercise and the stress system. Hormones (Athens) 4, 73-89.

Michopoulos, V., Higgins, M., Toufexis, D., Wilson, M.E., 2012. Social subordination produces distinct stress-related phenotypes in female rhesus monkeys. Psychoneuroendocrinology 37, 1071-1085. doi:10.1016/j.psyneuen.2011.12.004

Miller, D.A., Vleck, C.M., Otis, D.L., 2009. Individual variation in baseline and stress-induced corticosterone and prolactin levels predicts parental effort by nesting mourning doves. Horm. Behav. 56, 457-464. doi:10.1016/j.yhbeh.2009.08.001

Mumme, R.L., 1992. Do helpers increase reproductive success? An experimental analysis in the Florida scrub jay. Behav. Ecol. Sociobiol. 31, 319-328.

Nakagawa, S., Schielzeth, H., 2013. A general and simple method for obtaining R2 from generalized linear mixed-effects models. Methods Ecol. Evol. 4, 133-142. doi:10.1111/j.2041-210x.2012.00261.x 
956

957

958

959

960

961

962

963

964

965

966

967

968

969

970

971

972

973

974

975

976

977

978

979

980

981

982

983

984

985

986

987

988

989

990

991

992

993

994

995

996

997

998

999

1000

1001

Narayan, E.J., Cockrem, J.F., Hero, J.-M.M., 2013. Repeatability of baseline corticosterone and short-term corticosterone stress responses, and their correlation with testosterone and body condition in a terrestrial breeding anuran (Platymantis vitiana). Comp. Biochem. Physiol. A. Mol. Integr. Physiol. 165, 304-312. doi:10.1016/j.cbpa.2013.03.033

Ouyang, J.Q., Hau, M., Bonier, F., 2011. Within seasons and among years: when are corticosterone levels repeatable? Horm. Behav. 60, 559-564. doi:10.1016/j.yhbeh.2011.08.004

Ouyang, J.Q., Quetting, M., Hau, M., 2012. Corticosterone and brood abandonment in a passerine bird. Anim. Behav. 84, 261-268. doi:10.1016/j.anbehav.2012.05.006

Øverli, Ø., Sørensen, C., Pulman, K.G.T., Pottinger, T.G., Korzan, W., Summers, C.H., Nilsson, G.E., 2007. Evolutionary background for stress-coping styles: relationships between physiological, behavioral, and cognitive traits in non-mammalian vertebrates. Neurosci. Biobehav. Rev. 31, 396-412. doi:10.1016/j.neubiorev.2006.10.006

Owen, J.C., 2011. Collecting, processing, and storing avian blood: a review. J. Field Ornithol. 82, 339-354. doi:10.1111/j.1557-9263.2011.00338.x

Palacios, M.G., Sparkman, A.M., Bronikowski, A.M., 2012. Corticosterone and pace of life in two life-history ecotypes of the garter snake Thamnophis elegans. Gen. Comp. Endocrinol. 175, 443-448. doi:10.1016/j.ygcen.2011.11.042

Pettitt, A.N., 1980. A simple cumulative sum type statistic for the change-point problem with zero-one observations. Biometrika 67, 79-84. doi:10.2307/2335319

Pitk, M., Tilgar, V., Kilgas, P., Mänd, R., 2012. Acute stress affects the corticosterone level in bird eggs: a case study with great tits (Parus major). Horm. Behav. 62, 475-479. doi:10.1016/j.yhbeh.2012.08.004

Plyusnina, I.Z., Solov'eva, M.Y., Oskina, I.N., 2011. Effect of domestication on aggression in gray Norway rats. Behav. Genet. 41, 583-592. doi:10.1007/s10519-010-9429-y

Pottinger, T.G., Carrick, T.R., 1999. Modification of the plasma cortisol response to stress in rainbow trout by selective breeding. Gen. Comp. Endocrinol. 116, 122-132. doi:10.1006/gcen.1999.7355

R Core Team, 2015. R: A language and environment for statistical computing. R Foundation for Statistical Computing, Vienna, Austria. http://www.R-project.org/

Reeder, D.M., Kramer, K.M., 2005. Stress in free-ranging mammals: integrating physiology, ecology, and natural history. J. Mammal. 86, 225-235.

Rees, A., Harvey, S., 1987. Adrenocortical responses of pigeons (Columba livia) to treadwheel exercise. Gen. Comp. Endocrinol. 65, 117-120.

Rees, A., Harvey, S., Phillips, J.G., 1985. Transitory corticosterone responses of ducks (Anas platyrhynchos) to exercise. Gen. Comp. Endocrinol. 59, 100-104.

Rensel, M.A., Schoech, S.J., 2011. Repeatability of baseline and stress-induced corticosterone levels across early life stages in the Florida scrub-jay (Aphelocoma coerulescens). Horm. Behav. 59, 497-502. doi:10.1016/j.yhbeh.2011.01.010

Romero, L.M., 2002. Seasonal changes in plasma glucocorticoid concentrations in free-living vertebrates. Gen. Comp. Endocrinol. 128, 1-24.

Romero, L.M., 2004. Physiological stress in ecology: lessons from biomedical research. Trends Ecol. Evol. 19, 249-255. doi:10.1016/j.tree.2004.03.008

Romero, L.M., Meister, C.J., Cyr, N.E., Kenagy, G.J., Wingfield, J.C., 2008. Seasonal glucocorticoid responses to capture in wild free-living mammals. Am. J. Physiol. - Regul. Integr. Comp. Physiol. 294, R614-R622. doi:10.1152/ajpregu.00752.2007 
1002

1003

1004

1005

1006

1007

1008

1009

1010

1011

1012

1013

1014

1015

1016

1017

1018

1019

1020

1021

1022

1023

1024

1025

1026

1027

1028

1029

1030

1031

1032

1033

1034

1035

1036

1037

1038

1039

1040

1041

1042

1043

1044

1045

Romero, L.M., Reed, J.M., 2005. Collecting baseline corticosterone samples in the field: is under 3 min good enough? Comp. Biochem. Physiol. A. Mol. Integr. Physiol. 140, 73-79. doi:10.1016/j.cbpb.2004.11.004

Romero, L.M., Reed, J.M., Wingfield, J.C., 2000. Effects of weather on corticosterone responses in wild free-living passerine birds. Gen. Comp. Endocrinol. 118, 113-122. doi:10.1006/gcen.1999.7446

Romero, L.M., Soma, K.K., Wingfield, J.C., 1998. Hypothalamic-pituitary-adrenal axis changes allow seasonal modulation of corticosterone in a bird. Am. J. Physiol. Regul. Integr. Comp. Physiol. 274, R1338-R1344.

Romero, L.M., Wikelski, M., 2001. Corticosterone levels predict survival probabilities of Galapagos marine iguanas during El Niño events. Proc. Natl. Acad. Sci. U. S. A. 98, 7366-7370. doi:10.1073/pnas.131091498

Romero, L.M., Wingfield, J.C., 1998. Seasonal changes in adrenal sensitivity alter corticosterone levels in Gambel's white-crowned sparrows (Zonotrichia leucophrys gambelii). Comp. Biochem. Physiol. Comp. Pharmacol. Toxicol. Endocrinol. 119C, 31-36.

Ros, A.F.H., Vullioud, P., Bruintjes, R., Vallat, A., Bshary, R., 2014. Intra- and interspecific challenges modulate cortisol but not androgen levels in a year-round territorial damselfish. J. Exp. Biol. 217, 1768-1774. doi:10.1242/jeb.093666

Rubenstein, D.R., 2007. Stress hormones and sociality: integrating social and environmental stressors. Proc. R. Soc. Lond. B Biol. Sci. 274, 967-975. doi:10.1098/rspb.2006.0051

Saino, N., Romano, M., Ferrari, R.P., Martinelli, R., Møller, A.P., 2005. Stressed mothers lay eggs with high corticosterone levels which produce low-quality offspring. J. Exp. Zool. Part A Comp. Exp. Biol. 303, 998-1006. doi:10.1002/jez.a.224

Sapolsky, R.M., Romero, L.M., Munck, A.U., 2000. How do glucocorticoids influence stress responses? Integrating permissive, suppressive, stimulatory, and preparative actions. Endocr. Rev. 21, 55-89. doi:10.1210/er.21.1.55

Schielzeth, H., 2010. Simple means to improve the interpretability of regression coefficients. Methods Ecol. Evol. 1, 103-113. doi:10.1111/j.2041-210X.2010.00012.x

Schmid, B., Tam-Dafond, L., Jenni-Eiermann, S., Arlettaz, R., Schaub, M., Jenni, L., 2013. Modulation of the adrenocortical response to acute stress with respect to brood value, reproductive success and survival in the Eurasian hoopoe. Oecologia 173, 33-44. doi:10.1007/s00442-013-2598-7

Schoech, S.J., Bowman, R., Bridge, E.S., Boughton, R.K., 2007. Baseline and acute levels of corticosterone in Florida Scrub-Jays (Aphelocoma coerulescens): effects of food supplementation, suburban habitat, and year. Gen. Comp. Endocrinol. 154, 150-160. doi:10.1016/j.ygcen.2007.05.027

Schoech, S.J., Mumme, R.L., Moore, M.C., 1991. Reproductive endocrinology and mechanisms of breeding inhibition in cooperatively breeding Florida scrub jays (Aphelocoma $c$. coerulescens). Condor 93, 354-364.

Schoech, S.J., Rensel, M.A., Heiss, R.S., 2011. Short- and long-term effects of developmental corticosterone exposure on avian physiology, behavioral phenotype, cognition, and fitness : A review. Curr. Zool. 57, 514-530.

Schoech, S.J., Rensel, M.A., Wilcoxen, T.E., 2012. Here today, not gone tomorrow: long-term effects of corticosterone. J. Ornithol. 153, 217-226. doi:10.1007/s10336-012-0820-8 
1046

1047

1048

1049

1050

1051

1052

1053

1054

1055

1056

1057

1058

1059

1060

1061

1062

1063

1064

1065

1066

1067

1068

1069

1070

1071

1072

1073

1074

1075

1076

1077

1078

1079

1080

1081

1082

1083

1084

1085

1086

1087

1088

1089

1090

Schoech, S.J., Romero, L.M., Moore, I.T., Bonier, F., 2013. Constraints, concerns and considerations about the necessity of estimating free glucocorticoid concentrations for field endocrine studies. Funct. Ecol. 27, 1100-1106. doi:10.1111/1365-2435.12142

Schwabl, H., Bairlein, F., Gwinner, E., 1991. Basal and stress-induced corticosterone levels of garden warblers, Sylvia borin, during migration. J. Comp. Physiol. B 161, 576-580. doi:10.1007/BF00260747

Sheriff, M.J., Dantzer, B., Delehanty, B., Palme, R., Boonstra, R., 2011. Measuring stress in wildlife: techniques for quantifying glucocorticoids. Oecologia 166, 869-887. doi:10.1007/s00442-011-1943-y

Sih, A., Cote, J., Evans, M., Fogarty, S., Pruitt, J., 2012. Ecological implications of behavioural syndromes. Ecol. Lett. 15, 278-289. doi:10.1111/j.1461-0248.2011.01731.x

Sih, A., Del Giudice, M., 2012. Linking behavioural syndromes and cognition: a behavioural ecology perspective. Philos. Trans. R. Soc. Lond. B. Biol. Sci. 367, 2762-2772. doi:10.1098/rstb.2012.0216

Singh, A., Petrides, J.S., Gold, P.W., Chrousos, G.P., Deuster, P.A., 1999. Differential hypothalamic-pituitary-adrenal axis reactivity to psychological and physical stress. J. Clin. Endocrinol. Metab. 84, 1944-1948. doi:10.1210/jcem.84.6.5746

Slawik, M., Reisch, N., Zwermann, O., Maser-Gluth, C., Stahl, M., Klink, A., Reincke, M., Beuschlein, F., 2004. Characterization of an adrenocorticotropin (ACTH) receptor promoter polymorphism leading to decreased adrenal responsiveness to ACTH. J. Clin. Endocrinol. Metab. 89, 3131-3137. doi:10.1210/jc.2003-032010

Small, T.W., Schoech, S.J., 2015. Sex differences in the long-term repeatability of the acute stress response in long-lived, free-living Florida scrub-jays (Aphelocoma coerulescens). J. Comp. Physiol. [B] 185, 119-133. doi:10.1007/s00360-014-0866-4

Spencer, R.L., Kim, P.J., Kalman, B.A., Cole, M.A., 1998. Evidence for mineralocorticoid receptor facilitation of glucocorticoid receptor-dependent regulation of hypothalamicpituitary-adrenal axis activity. Endocrinology 139, 2718-2726. doi:10.1210/endo.139.6.6029

Summers, C.H., Watt, M.J., Ling, T.L., Forster, G.L., Carpenter, R.E., Korzan, W.J., Lukkes, J.L., Øverli, Ø., 2005. Glucocorticoid interaction with aggression in non-mammalian vertebrates: Reciprocal action. Eur. J. Pharmacol. 526, 21-35. doi:10.1016/j.ejphar.2005.09.059

Suzuki, K., Yamada, H., Kobayashi, T., Okanoya, K., 2012. Decreased fecal corticosterone levels due to domestication: a comparison between the white-backed munia (Lonchura striata) and its domesticated strain, the Bengalese finch (Lonchura striata var. domestica) with a suggestion for complex song evolution. J. Exp. Zool. Part A Ecol. Genet. Physiol. 317, 561-570. doi:10.1002/jez.1748Taff, C.C., Vitousek, M.N., 2016. Endocrine Flexibility: Optimizing Phenotypes in a Dynamic World? Trends Ecol. Evol. 31, 476488. doi:10.1016/j.tree.2016.03.005

Takahara, T., Minamoto, T., Doi, H., Ito, T., Kawabata, Z., 2014. Differences between domesticated Eurasian and Japanese indigenous strains of the common carp (Cyprinus carpio) in cortisol release following acute stress. Ichthyol. Res. 61, 165-168. doi:10.1007/s10228-013-0385-4

Taylor, W.A., 2000. Change-Point Analysis: a powerful new tool for detecting changes. URL http://www.variation.com/cpa/tech/changepoint.html 
1091

1092

1093

1094

1095

1096

1097

1098

1099

1100

1101

1102

1103

1104

1105

1106

1107

1108

1109

1110

1111

1112

1113

1114

1115

1116

1117

1118

1119

1120

1121

1122

1123

1124

1125

1126

1127

1128

1129

1130

1131

1132

1133

1134

1135

1136

Trut, L., Oskina, I., Kharlamova, A., 2009. Animal evolution during domestication: the domesticated fox as a model. BioEssays 31, 349-360. doi:10.1002/bies.200800070

Van Duyse, E., Pinxten, R., Darras, V.M., Arckens, L., Eens, M., 2004. Opposite changes in plasma testosterone and corticosterone levels following a simulated territorial challenge in male great tits. Behaviour 141, 451-467.

Veenema, A.H., Koolhaas, J.M., De Kloet, E.R., 2004. Basal and stress-induced differences in HPA axis, 5-HT responsiveness, and hippocampal cell proliferation in two mouse lines. Ann. N. Y. Acad. Sci. 1018, 255-265. doi:10.1196/annals.1296.030

Verbeek, P., Iwamoto, T., Murakami, N., 2008. Variable stress-responsiveness in wild type and domesticated fighting fish. Physiol. Behav. 93, 83-88. doi:10.1016/j.physbeh.2007.08.008

Versteegh, M.A., Schwabl, I., Jaquier, S., Tieleman, B.I., 2012. Do immunological, endocrine and metabolic traits fall on a single Pace-of-Life axis? Covariation and constraints among physiological systems. J. Evol. Biol. 25, 1864-1876. doi:10.1111/j.14209101.2012.02574.x

Vitousek, M.N., Jenkins, B.R., Safran, R.J., 2014. Stress and success: individual differences in the glucocorticoid stress response predict behavior and reproductive success under high predation risk. Horm. Behav. 66, 812-819. doi:10.1016/j.yhbeh.2014.11.004

Wada, H., Salvante, K.G., Stables, C., Wagner, E., Williams, T.D., Breuner, C.W., 2008. Adrenocortical responses in zebra finches (Taeniopygia guttata): individual variation, repeatability, and relationship to phenotypic quality. Horm. Behav. 53, 472-480.

Wallace, D., Green, S.B., 2002. Analysis of repeated measures designs with linear mixed models, in: Moskowitz, D.S., Hershberger, S.L. (Eds.), Modeling Intraindividual Variability with Repeated Measures Data: Methods and Applications, Multivariate Applications Book Series. Lawrence Erlbaum Associates Publishers, Mahwah, NJ, US, pp. 103-134.

Wilcoxen, T.E., Boughton, R.K., Bridge, E.S., Rensel, M.A., Schoech, S.J., Reynolds, S.J., 2011. Age-related differences in baseline and stress-induced corticosterone in Florida scrubjays. Gen. Comp. Endocrinol. 173, 461-466. doi:10.1016/j.ygcen.2011.07.007

Wingfield, J.C., O'Reilly, K.M., Astheimer, L.B., 1995. Modulation of the adrenocortical responses to acute stress in arctic birds: a possible ecological basis. Am. Zool. 35, 285294.

Wingfield, J.C., Vleck, C.M., Moore, M.C., 1992. Seasonal changes of the adrenocortical response to stress in birds of the Sonoran Desert. J. Exp. Zool. 264, 419-428. 


\section{Table 1}

1138 Nonparametric change-point detection results for the first change-point detected in samples

1139 collected up to 3 min post-capture based on all jays (All) or jays subdivided by SI-CORT

1140 phenotype (High, Med, Low).

1141

\begin{tabular}{|c|c|c|c|c|c|c|}
\hline$S I-C O R T$ & $n$ & $\begin{array}{l}\text { Time range } \\
(\mathrm{min})\end{array}$ & $\begin{array}{c}\text { Change- } \\
\text { Point (min) }\end{array}$ & $\begin{array}{c}95 \% \text { CI } \\
\text { (min) }\end{array}$ & $\begin{array}{l}\text { Conf. } \\
\text { Level }\end{array}$ & 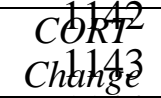 \\
\hline All & 387 & $0.75-3.0$ & 1.97 & $1.90,2.13$ & $99 \%$ & $3.01 / 3.444$ \\
\hline High & 119 & $0.75-3.0$ & 2.12 & $1.67,2.35$ & $97 \%$ & $3.56 / 44950$ \\
\hline Med & 140 & $0.77-3.0$ & 1.82 & $1.52,2.37$ & $100 \%$ & $2.86 / B 465$ \\
\hline Low & 128 & $0.83-3.0$ & 1.80 & $1.67,2.27$ & $99 \%$ & $2.39 / 24866$ \\
\hline
\end{tabular}

1148

1149 95\% confidence intervals (CI) and confidence levels (Conf. Level) are based on 10,000 bootstrap

1150 simulations.

1151 CORT Change shows the average CORT value (ng/ml) before and after the change-point (before/after).

1152

1153

1154

1155

1156

1157

1158

1159

1160

1161

1162

1163 


\section{Table 2}

1165 A) Effect of SI-CORT phenotype, time since capture (Time), and sex on single CORT (ng/ml)

1166 samples collected within 3 min of capture $(n=387$ samples; 2011-2014). B) Effect of SI-CORT

1167 phenotype and Time on individuals sampled 2 or 3 times within 3 min of capture $(n=37$ birds;

116883 samples; 2013). SI-CORT and Time were analyzed at continuous data.

1169

1170

1171

1172

1173

1174

1175

1176

1177

1178

1179

1180

1181

1182

1183

1184

1185

1186

1187

1188

1189

1190

1191

1192

1193

1194

\begin{tabular}{|c|c|c|c|c|}
\hline Fixed & $F(d f)$ & $p$ & $\beta$ & $\beta 95 \% C I$ \\
\hline \multicolumn{5}{|c|}{ A) Single sample/l ${ }^{\text {st }}$ sample } \\
\hline SI-CORT (C) & $23.1(1,283.7)$ & $<0.0001$ & 0.23 & $0.13,0.32$ \\
\hline Time $(\mathrm{T})$ & $13.6(1,3$ & 0.0003 & 0.19 & .28 \\
\hline $\operatorname{Sex}(\mathrm{S})$ & $1.08(1,16$ & 0.3012 & -0.05 & $-0.14,0.04$ \\
\hline $\mathrm{C} \times \mathrm{T}$ & $0.25(1,3$ & 0.6200 & 0.02 & $-0.06,0.11$ \\
\hline $\mathrm{C} \times \mathrm{S}$ & $0.51(1$ & 0.4 & 0.03 & $-0.06,0.13$ \\
\hline $\mathrm{T} \times \mathrm{S}$ & $0.25(1$, & 0.6 & -0.02 & $-0.12,0.07$ \\
\hline $\mathrm{C} \times \mathrm{T} \times \mathrm{S}$ & $1.26(1$ & 0.2623 & 0.05 & 0.13 \\
\hline \multicolumn{5}{|c|}{ B) Repeated sampling } \\
\hline SI-CORT (C) & $29.8(1,35.3)$ & $<0.0001$ & 0.57 & 0.78 \\
\hline Time $(\mathrm{T})$ & $96.5(1,4$ & $<0.0001$ & 0.39 & $0.31,0.48$ \\
\hline $\mathrm{C} \times \mathrm{T}$ & $30.8(1,47.9)$ & $<0.0001$ & 0.25 & $0.16,0.34$ \\
\hline
\end{tabular}

$\begin{array}{lllll}\text { SI-CORT }(C) & 29.8(1,35.3) & <\mathbf{0 . 0 0 0 1} & 0.57 & 0.36,0.78\end{array}$

\section{5}


1197 Table 3

1198 Conditional (Con; fixed and random factors) and marginal (Mar; only fixed factors) $\mathrm{R}_{\text {GLMM }}^{2}$

$1199\left(R^{2} G\right)$ values for linear-mixed models (Nakagawa and Schielzeth, 2013) with either stress-

1200 induced CORT (SI-CORT), time since capture (Time), or a model containing SI-CORT, Time,

1201 and their interaction (Whole) for CORT samples collected within 1.5 min of capture $(<1.5 \mathrm{~min})$

1202 or within 3 min of capture (3 min). All models contained sampling year (2011-2014) as a random

1203 variable.

1204

1205

1206

1207

1208

1209

1210

1211

1212

1213

1214

1215

1216

1217

1218

1219

1220

1221

1222

1223

\begin{tabular}{lcccc}
\hline \multirow{3}{*}{ Model } & \multicolumn{2}{c}{$<$ l.5min } & \multicolumn{2}{c}{$<3$ min } \\
& Mar & Con & Mar & Con \\
& $R^{2} G$ & $R^{2} G$ & $R^{2} G$ & $R^{2}{ }_{G}$ \\
\hline SI-CORT & 0.11 & 0.18 & 0.12 & 0.32 \\
Time & 0.00 & 0.09 & 0.08 & 0.29 \\
Sex & na & na & 0.00 & 0.20 \\
Whole & 0.13 & 0.21 & 0.18 & 0.34 \\
\hline
\end{tabular}




\section{Table 4}

1226 Effect of trapping effort (Effort; the elapsed time between trap deployment and capture) on initial

1227 CORT values in birds caught in 2013- 2014 (without repeated measures). SI-CORT phenotype

1228 and time since capture (Time) were included as continuous variables to investigate interaction

1229 effects on plasma CORT samples from jays that had experienced between 1.2-169 min of

1230 exposure to the trap prior to capture (All pre), and then were sampled within A) 1.5 min of

1231 capture $(<1.5 \min$ post; $\mathrm{n}=43)$ or $\mathrm{B}) 3 \min$ of capture $(<3 \min$ post; $\mathrm{n}=178)$. C) Jays caught

1232 within 10 min of pre-capture trap exposure (<10 min pre) and then sampled within 2 min post-

1233 capture $(<2$ min post; $\mathrm{n}=28)$.

\begin{tabular}{lcccccc}
\hline & A) All pre, $<1.5$ min post & \multicolumn{2}{c}{ B) All pre, <3 min post } & \multicolumn{2}{c}{ C) $<10$ min pre, $<2$ min post } \\
Fixed & $F(d f)$ & $p$ & $F(d f)$ & $p$ & $F(d f)$ & $p$ \\
\hline SI-CORT $(\mathrm{C})$ & $11.5(1,32)$ & $\mathbf{0 . 0 0 1 8}$ & $19.8(1,162.6)$ & $<\mathbf{0 . 0 0 0 1}$ & $8.88(1,20)$ & $\mathbf{0 . 0 0 7 4}$ \\
Time (T) & $0.71(1,32)$ & 0.4070 & $11.9(1,161.3)$ & $\mathbf{0 . 0 0 0 7}$ & $2.71(1,20)$ & 0.1151 \\
Effort (E) & $1.88(1,32)$ & 0.1797 & $0.34(1,163)$ & 0.5580 & $0.00(1,20)$ & 0.9453 \\
C $\times$ T & $0.00(1,32)$ & 0.9502 & $0.33(1,166)$ & 0.5675 & $0.00(1,20)$ & 0.9495 \\
C $\times$ E & $0.04(1,32)$ & 0.8486 & $0.03(1,144.2)$ & 0.8534 & $0.06(1,20)$ & 0.8079 \\
T $\times$ E & $1.84(1,32)$ & 0.1850 & $1.70(1,165.9)$ & 0.1939 & $1.14(1,20)$ & 0.2983 \\
C $\times$ T $\times$ E & $1.63(1,32)$ & 0.2104 & $0.02(1,138.5)$ & 0.8875 & $2.09(1,20)$ & 0.1636 \\
\hline
\end{tabular}

1234

1235

1236

1237

1238

1239

1240

1241 


\section{Figure Legends}

1245 Fig. 1. General characteristics of the stress-induced corticosterone (SI-CORT) response of 1246 Florida scrub-jays. A) Variation in plasma CORT concentration in response to being captured 1247 and held for 30 min (SI-CORT). Stress responses have been divided into Low (N=78), medium

1248 (Med; $\mathrm{N}=77)$, and High $(\mathrm{N}=78)$ ranks. $\mathrm{B})$ Rate of increase in corticosterone (CORT) levels in the

1249 blood between sampling time points. Bars not sharing a letter are different $(\mathrm{P}<0.05$; Tukey-

1250 Kramer HSD test; also see Table 2) and shading of bars matches the legend in panel A. Data

1251 points (A) and bars (B) represent means \pm standard errors (error bars).

1252

1253

1254

1255

1256

1257

1258

1259

1260

1261

1262

1263

1264 
1265 Fig. 2. Raw CORT values collected within 3 min of capture. A) Values from birds sampled once 1266 within 3 min of capture in 2011-2014. White points and solid lines are birds with High stress1267 induced CORT (SI-CORT), gray points and dashed lines are medium (Med) SI-CORT, and black 1268 points and dotted lines are Low SI-CORT. B) A representative subset of values from nine birds 1269 repeatedly sampled ( 2 or 3 times) within 3 min of capture in 2013. Each line connects the CORT 1270 values for one individual. For the purpose of comparison, the subset was limited to birds with a 1271 CORT concentration between 1-2 ng/ml for their first sample collected within 2 min of capture, 1272 and a last sample collected between 2.5-3 min.

1273

1274

1275

1276

1277

1278

1279

1280

1281

1282

1283

1284

1285

1286

1287 
1288 Fig. 3. Changes in initial CORT concentrations as a function of time since capture and the 1289 individual's stress-induced CORT phenotype (SI-CORT). A) Values from birds sampled once 1290 within 3 min of capture in 2011-2014. B) Values from birds repeatedly sampled (2 or 3 times) 1291 within 3 min of capture in 2013. SI-CORT phenotypes are divided into Low, Medium (Med), or 1292 High groups. Time since capture is divided into samples collected between $0.75-1.5 \min (<1.5$ $1293 \mathrm{~min}$ ), 1.5-2.0 $\mathrm{min}, 2.0-2.5 \mathrm{~min}$, and 2.5-3.0 min post-capture. Sample sizes are shown at the base 1294 of each bar. Averages across SI-CORT phenotypes are shown as points connected with a dashed 1295 line. Bars and points are means ( \pm standard error). Points that do not share a letter are 1296 significantly different $(\mathrm{P}<0.05)$. Differences between bars are described in the Results section. 1297 1298 1299 1300 1301 1302 1303 1304 1305 1306 1307 1308 1309 1310 
1311 Fig. 4. The relationship of initial CORT and stress-induced CORT (SI-CORT) in 113 Florida

1312 scrub-jays sampled within $1.5 \mathrm{~min}$ of capture (2011-2014). Dashed lines indicate the divisions

1313 between high $(>760[\mathrm{ng} / \mathrm{ml}] \times \min )$, medium, and low $(<565)$ SI-CORT categories used in

1314 other analyses. Gray area is the 95\% confidence interval around the line. Conditional (Con; fixed

1315 and random factors) and marginal (Mar; only fixed factors) $\mathrm{R}_{\mathrm{GLMM}}^{2}\left(R^{2} G\right)$ values for linear-mixed

1316 models are based on Nakagawa and Schielzeth (2013). 


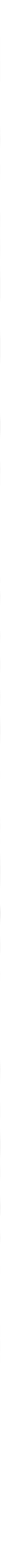


Individual samples $<3$ min Subset of repeat samples

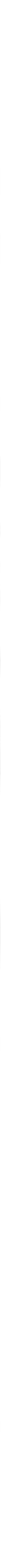




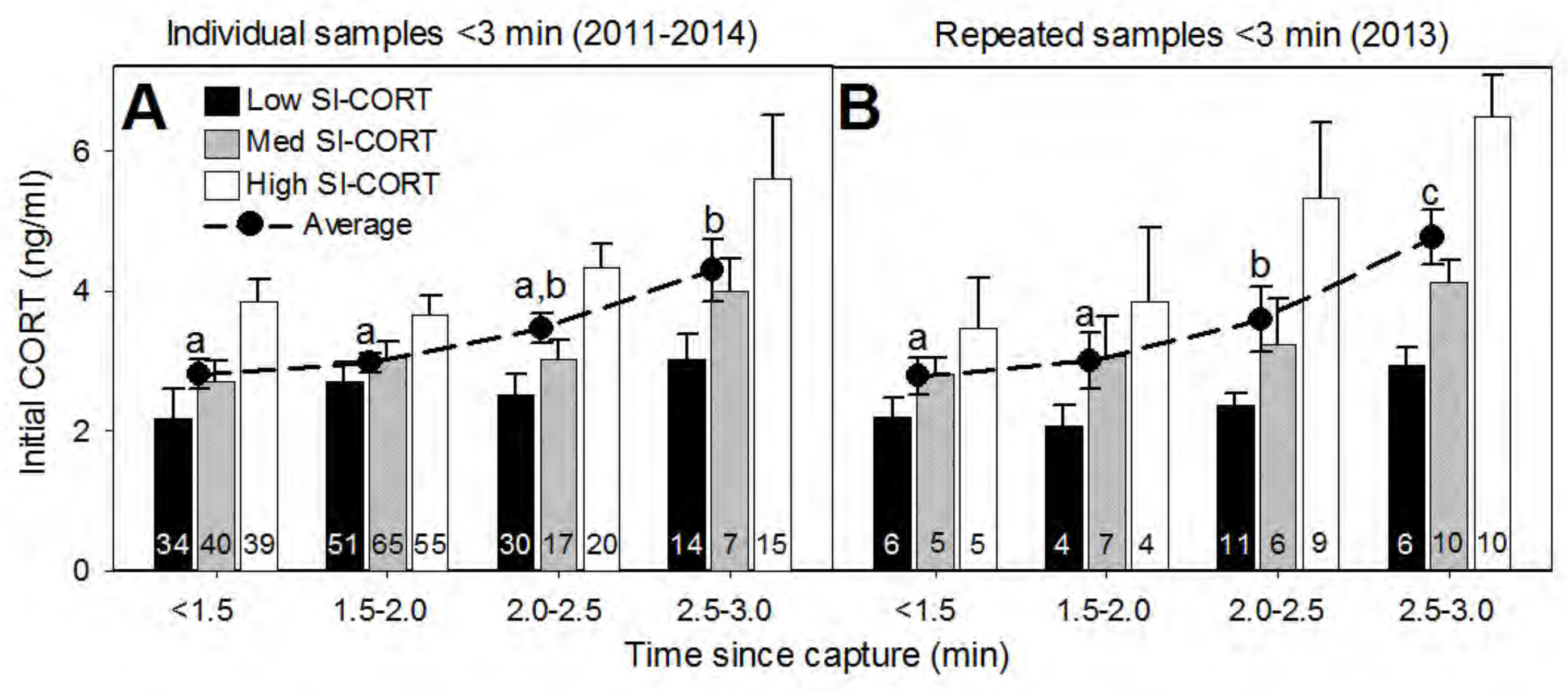




\section{Collected under 1.5 minutes}

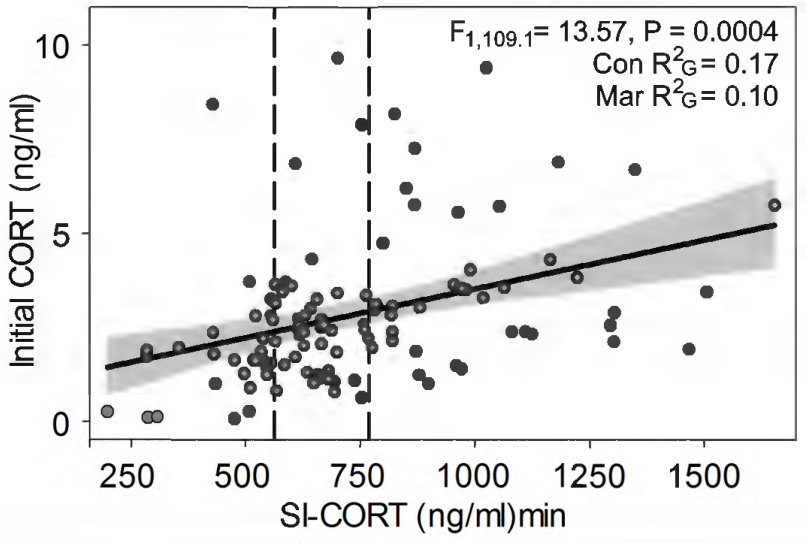

